\title{
Aptidão física e actividade física em populações Africanas: Uma revisão da literatura
}

\author{
Leonardo N hantumbo1,3 \\ Sílvio Saranga 1,3 \\ André Seabra² \\ José Maia² \\ António Prista 1,3
}

https://doi.org/10.5628/ppcd.06.03.373

\author{
1 Faculdade de Ciências de Educação Física e D esporto \\ Universidade Pedagógica \\ M oçambique \\ ${ }^{2}$ Faculdade de Desporto \\ U niversidade do Porto \\ Portugal \\ ${ }^{3}$ Laboratório de Fisiologia do Exercício \\ DCD - Universidade Eduardo M ondlane \\ Maputo \\ M oçambique
}

\section{RESUMO}

O estabelecimento de relações entre a aptidão física e saúde a partir de uma óptica epidemiológica deriva, de entre outras razões, do incremento conspícuo do sedentarismo que se observa nos países industrial izado e que se apresenta associado a uma multiplicidade de factores de condições mórbidas. Em África, face à predominância de actividades de sobrevivência o sedentarismo e suas comorbilidades não se afiguram como prioridade ou matéria de relevo. Contudo, as preocupações em torno da aptidão física neste continente, ainda que de panorama distinto, são pertinentes face a crescente urbanização das sociedades Africanas tem concorrido para o incremento dos níveis de hipocinésia, o que começa a inquietar as autoridades sanitárias. A presente revisão da literatura foi realizada com o propósito de minorar a escassez e dispersão da pesquisa em populações Africanas. Recorrendo à consulta de bases disponíveis, foram seleccionados todos os artigos que versassem estudos realizados em África com indexação aptidão física e actividade física. Dos estudos revistos emerge (1) uma inquietação em torno do alcance antropobiológico da expressão da aptidão física e dos padrões de actividade física das populações africanas de diferentes idades, grupos étnicos e estratos sócio-económicos, designadamente da influência stress ambiental, do estado nutricional e das infecções parasitárias na variabilidade da sua expressão e (2) o facto da avaliação da aptidão física e dos critérios de normalização estatural se basearem em valores de referência construídos a partir de amostras de países desenvolvidos emprestarem a este processo problemas de transculturalidade, têm ultimamente suscitado polémica e investigação sobre a sua validade.

Palavras-Chave: aptidão física, actividade física, África, saúde pública, epidemiologia.

\section{ABSTRACT}

Physical Fitness and Physical Activity in Africa. State of the Art

The established link between physical fitness and health is based on epidemiological evidence about sedentary lifestyles associated with multiple factors of morbid conditions. In Africa, survival activities demanding a lot of energy expenditure and moderate to high levels of physical fitness are not correlated with sedentary and its co-morbidities. Due to this major reason, no special attention was given to the relationship between fitness and health. Yet, there has been an increased interest and research about physical fitness of African children and adolescents due to the fact the urbanization is increasing in small to big African cities, and its potentiality in reducing physical activity levels. Such a fact is becoming a concern of health authorities. The present literature review was conducted with the aim of synthesising the available information. Based on a data base search, we selected all indexed papers with Africa, physical activity and physical fitness. From this search, two main issues are at hand: (1) a discussion about the clear anthropobiological meaning of physical fitness and physical activity patterns of African population of different ages, ethnicity, and socio-economic strata with a special emphasis on environmental stress, nutritional status and infection; (2) the fact that physical fitness assessment and normalizing criteria to height are based on reference data from developed countries that pose cross-cultural validity problems.

Key-words: physical fitness, physical activity, Africa, public health, epidemiology. 


\section{INTRODUÇÃO}

O incremento galopante do sedentarismo da sociedade moderna industrial izada tem conduzido à sua associação a factores de risco de um complexo espectro de condições mórbidas, bem como ao estabelecimento de relações entre aptidão física e saúde, fundamentalmente a partir de uma óptica epidemiológica. É assim que, nos países desenvolvidos, as consequências marcadamente nefastas do sedentarismo têm condicionado uma parte substancial da atenção de epidemiologistas da actividade física, não só em torno da inactividade física e da sua associação a factores mórbidos, como também, e sobretudo, da apropriação da aptidão física na sua relação com a saúde $(12,13,50)$. É pois nesta perspectiva de saúde que as Ciências do Desporto têm conhecido, nas últimas décadas, um crescimento substancial da investigação. Sendo África um continente onde a maior parte da população vive fundamentalmente na base de actividades de subsistência, e porque desprovido de meios e condições eficazes de monitorização e controlo de calamidades, como as secas e cheias cídicas, o problema do sedentarismo e suas comorbilidades não constitui prioridade ou assunto de realce. Obviamente, os serviços de saúde em África continuam a ser confrontados com a busca de soluções de problemas derivados de constrangimentos nutricionais e de endemias infecto-contagiosas. É assim que o estudo da capacidade funcional das populações Africanas se tem desenrolado de forma escassa e dispersa. Há contudo a considerar que nos países não desenvolvidos, como é o caso da maioria dos países de África, a eficiência em realizar trabal ho é determinante, o que torna a capacidade funcional de um grupo populacional um elemento essencial para a sua capacidade produtiva(14, 51, 61). É desta forma que, as preocupações com a aptidão física em Africa, se bem que de perspectiva distinta, não deixam de se apresentar como pertinentes. Mais, a crescente urbanização das sociedades Africanas tem evoluído para o crescimento do sedentarismo que começa a preocupar as autoridades sanitárias.

O reconhecimento da influência da pressão ambiental sobre a expressão da aptidão física tem favorecido o interesse pelos estudos em África, já que persistem neste continente condições "ecológicas" singulares de pesquisa e já difíceis de encontrar noutros luga- res. Originalmente, a pesquisa relativa à aptidão parecia confinada ao efeito da estatura na performance corporal, já que apresentando-se as crianças africanas geral mente mais baixas e mais magras relativamente às crianças americanas e europeias, haveria todo o interesse em estabelecer o seu efeito na performance motora. A influência do meio ambiente no tamanho e no físico foram já estudadas há cerca de trinta e sete anos por Hiernaux (35) através de uma revisão de dados referentes a mais de quatrocentas etnias habitantes da região de África Sub-Sahariana, tendo constatado que valores estaturais el evados estavam associados a um clima seco e quente com al tas variações sazonais; a estatura baixa associavase a uma temperatura húmida e constante, enquanto que a massa corporal revelava uma afinidade com humidade e uma relação negativa com a altitude. Desde então que o ol har sobre a aptidão física em África tem percorrido, tímida e dispersamente, outros campos de visão, que no entanto se confinam maioritariamente em torno de fenómenos associados à estatura, como seja da influência do aporte nutricional e das insuficiências higinénico-sanitárias. Por outro lado, o facto da avaliação da aptidão física e critérios de normalização estatural se basearem em valores de referência construídos a partir de estudos realizados em países desenvolvidos, empresta a este processo problemas de transculturalidade que têm ultimamente suscitado polémica e investigação sobre a sua validade.

Do exposto, e dada a complexidade da realidade contextual Africana, emerge a ideia de que as manifestações de aptidão física em África adquirem complexidades de descrição e interpretação distintas das que caracterizam o mundo industrializado, conferindo ao seu estudo em África desafios singulares.

O presente trabal ho surge da necessi dade de congregar a informação disponível na literatura sobre a investigação em aptidão física em África de forma a contribuir para a sistematização dos problemas conceptuais, metodológicos e de interpretação. A partir da revisão dos estudos real izados em África sobre a aptidão física, espera-se com a presente revisão, não apenas disponibilizar na forma de artigo a informação sobre a temática, mas também contribuir para uma melhor estruturação da pesquisa sobre a aptidão física em África. 


\section{ESTUDOS DESCRITIVOS E COMPARATIVOS}

Uma parte considerável dos estudos publicados sobre a aptidão física em África consiste na descrição do padrão da aptidão em função do sexo e idade e na sobreposição dos valores às normas e dados publicados com populações do mundo industrializado. Estes estudos utilizam exclusivamente baterias de testes criadas em países desenvolvidos.

Utilizando a bateria da AAHPERD(1), Elnashir e Mayhew(22) avaliaram um total de 710 crianças egípcias de ambos os sexos (rapazes, $\mathrm{n}=399$; raparigas, $\mathrm{n}=311$ ) com idades compreendidas entre os 9 e os 18 anos. Relativamente às normas americanas, as crianças egípcias apresentaram resultados mais baixos em quase todos os testes, com excepção do teste de força de braços até aos 14 anos nos rapazes, e no teste de tempo de suspensão na barra nas raparigas, mas apenas no intervalo etário dos 9-11 anos. Os autores especulam que os resultados encontrados podem ser explicados pela menor estatura, os baixos níveis de actividade física, a insuficiência nutricional, bem como razões culturais, porém não é apresentada qualquer evidência que sustente estas afirmações. No Zaire, Ghesquiere et al.(31) administraram a bateria do EUROFIT em crianças e jovens da floresta Ituri e relacionaram os seus resultados com valores de crianças e jovens europeias. A generalidade dos resultados encontrados deu a indicação de que os europeus tinham, em termos absolutos, melhores val ores nos testes de força de resistência abdominal, força de braços e agilidade, porém inferiores nos testes de equilíbrio, batimento de placas, impulsão horizontal sem corrida preparatória, flexibilidade e tempo de suspensão na barra. Perante este quadro de resultados, e com base no conhecimento da relação deste conjunto de testes com a composição corporal, os autores concluíram que os europeus eram melhores somente naqueles testes em que a maior estatura Ihes conferia vantagem, atribuindo à uma mais elevada actividade física habitual a performance dos africanos.

Ainda no Zaire, Nkiama(46) encontrou resultados idênticos com a aplicação da mesma bateria EU R OFIT numa população escolar de ambos os sexos, com idades compreendidas entre os 6 e os 20 anos. Sendo uma população mais baixa e magra, os seus valores da aptidão física sobrepostos aos resultados encon- trados com crianças e jovens Belgas revelaram supe rioridade dos belgas nos testes em que a influência da maturação e/ ou da altura é determinante. Ao ajustar os valores àquelas duas variáveis, o autor constatou que as diferenças deixavam de existir e, em alguns caso, se invertiam, tornando a estatura um elemento decisivo na explicação das diferenças. Prista(51) estudou 593 crianças e jovens de Maputo, Moçambique, tendo aplicado um conjunto de testes retirados das baterias de AAHPERD (1) E EUROFIT(23). A amostra integrou rapazes e raparigas dos 8 aos 15 anos e os resultados revelaram um perfil idêntico de aptidão física ao que é encontrado nos demais estudos, isto é, os rapazes são mais capazes em tarefas de força e resistência, enquanto que as raparigas evidenciaram maiores índices de flexibilidade. Contudo, as diferenças entre rapazes e raparigas em algumas tarefas foram inferiores ao que é normalmente encontrado nos estudos. Por outro lado, os resultados sobrepostos às normas da A A H PERD e estudos com Europeus revelaram performances marcadamente superiores dos Africanos, não apenas em tarefas onde a massa muscular absoluta é determinante, como também em termos de resistência cardiorespiratória, agilidade e flexibilidade. Nesse estudo, o autor demonstrou que os níveis de actividade física da população estudada, ligada a tarefas de sobrevivência e jogos activos ao ar livre poderiam explicar os bons níveis de performance encontrados. Ainda em Moçambique, num estudo realizado por Muria et al.(43) com o propósito de testar, em populações Africanas, os critérios sugeridos pela bateria da Prudential Fitnessgram, foram avaliadas 547 crianças e jovens dos 8 aos 11 anos de idade de ambos os sexos. Os resultados evidenciaram uma elevada proporção de sujeitos que ultrapassa o limite de aptidão física associada à saúde, para além da presença de valores percentuais superiores a $50 \%$ de crianças de ambos os sexos com valores iguais e/ ou superiores aos critérios adoptadas pelo Fitnessgram.

Faye et al.(25) numa pesquisa realizada sobre uma amostra de 700 de rapazes e raparigas Senegalesas, com idades compreendidas entre os 7 e os 13 anos de idade, estudaram a dinâmica da expressão de algumas capacidades físicas em função da idade e do género, nomeadamente velocidade, coordenação, potência, flexibilidade e equilíbrio. Os rapazes obti- 
veram mel hores resultados que as raparigas nos testes de velocidade e potência, enquanto que estas evidenciaram melhores performances nos testes de flexibilidade e de equilíbrio. Verificou-se ainda uma redução pronunciada seguida de um decréscimo nos níveis de prestação nos testes de velocidade e potência nas raparigas, contrariamente ao que se verificou nos rapazes, em que à excepção da flexibilidade, os níveis de aptidão física permaneceram estáveis, revelando em alguns casos aumentos significativos. No intuito de explicar o dimorfismo sexual, Maia et al.(38) avaliaram o efeito na aptidão física, da maturação biológica, do tamanho do corpo, do estatuto sócio-económico e da percentagem de gordura, em 2503 crianças e jovens de ambos os sexos (rapazes, $\mathrm{n}=1199$; raparigas, $\mathrm{n}=1304$ ) provenientes de várias regiões da cidade de Maputo, com idades que variavam entre os 8 e os 17 anos. A aptidão física foi avaliada através de nove provas provenientes das baterias do EUROFIT, Prudential Fitnessgram eAAHPERD. $O$ estudo confirmou o efeito determinante da idade e género mesmo depois de controlado o efeito da massa corporal, estágio maturacional e estatuto sócio-económico.

Em resumo, os escassos estudos descritivos e comparativos realizados em África confirmam a existência de um dimorfismo sexual e etário, idêntico, em termos de padrão, ao já estabelecido para os países do chamado mundo desenvolvido. Os rapazes são mais capazes em eventos de força e resistência, enquanto que as raparigas sobressaem no teste de flexibilidade. É evidente uma melhoria dos níveis de aptidão física em função da idade. Por outro lado, as crianças e jovens africanos apresentam valores de estatura e peso inferiores aos val ores normativos, e não obstante esse facto, à excepção dos testes em que a maior estatura constitui vantagem, apresentam melhores níveis de aptidão física nos demais testes em relação às crianças e jovens americanas e europeias.

\section{APTIDÃO FÍSICA, ALOMETRIA E ESTADO NUTRICIONAL} É consensual que, relativamente às populações dos países desenvolvidos, o crescimento em África se processa de forma mais lenta seguindo um padrão comum com al gumas variações locais dependendo das circunstâncias sociais, estado nutricional e grau de urbanização(14, 24). Relativamente às normas inter- nacionais, a média das dimensões corporais é consistentemente inferior nas crianças e jovens Africanas $(17,24,40,46,58)$. Assumindo que o desvio da taxa normal de crescimento de uma criança pode reflectir os efeitos de condições deficientes de nutrição e/ ou a presença de doenças infecciosas, critérios antropométricos foram adoptados como indicadores do estado nutricional, constituindo uma prática comum em saúde pública e em estudos epidemiológicos(67, 68, 69).

Tem sido polémica a classificação da normalidade em populações de países não desenvolvidos a partir de normas construídas em estudos realizados com crianças e jovens de países desenvolvidos(28, 32, 39). Embora se reconheça a influência desfavorável da malnutrição no crescimento infantil e juvenil, a classificação do estado nutricional duma criança a partir da posição percentílica que esta ocupa em relação a outros pode não ser suficiente $(14,53,58)$. Desta forma, a procura do significado da menor estatura de uma população relativamente a outra tem constituído uma preocupação. Dado que a prontidão física para o desempenho da vida é determinante, a influência da menor estatura descrita para os Africanos, em especial crianças e jovens, tem vindo a ser alvo de estudo.

A investigação real izada neste âmbito, e em contexto africano, abrange crianças em idade pré-escolar, em idade escolar, jovens e adultos jovens. Contudo, os estudos realizados com crianças em idade pré-escolar são bastante diminutos. Neste espaço etário existem três trabalhos disponíveis na literatura, sendo um realizado na Nigéria por Toriola e Igbokwe(65) e outros dois no Senegal por Bénéfice $(4,5)$. O estudo de Toriola e Igbokwe real izado em 341 crianças de ambos os sexos em idade pré-escolar ( 3 aos 5 anos) e pretendia comparar a sua performance motora em função do género e da idade cronológica. Os resultados evidenciaram uma tendência bastante linear de incremento dos níveis de performance dos grupos em função da idade, à excepção das raparigas nas provas de equilíbrio e corrida. Em todos os grupos etários, os rapazes obtiveram melhores resultados que as raparigas em quatro dos seis testes motores de que a bateria utilizada era composta. Foi assim possível verificar que já na infância as diferenças na performance motora em função do género e da idade cronológica eram evidentes. 
Nos estudos realizados no Senegal por Bénéfice pre tendia-se descrever o crescimento somático e o desenvolvimento da capacidade de trabalho em 88 crianças rurais saudáveis dos 3 aos 6 anos de ambos os sexos e avaliar o impacto do seu estado nutricional na resposta cardiovascular ao exercício bem como a relação entre o crescimento, funcionalidade e performance motora. Para além das medidas antropométricas, foram administrados os testes de 20 metros de corrida, impulsão horizontal sem corrida preparatória, força de preensão e arremesso de bola e um teste de degrau adaptado para crianças em idade préescolar. Os resultados confirmaram rácios de peso e altura e pregas de adi posi dade abaixo das medianas dos valores de referência da OMS e valores de aptidão física em todos os testes inferiores aos encontrados em europeus. Contudo, depois de normalizado para o tamanho corporal, as diferenças entre as crianças senegaleses e europeias diminuíram de forma relevante. Para além das questões alométricas, o autor considerou que a influência cultural na performance dos testes poderia explicar alguma desvantagem das crianças africanas, nomeadamente índices motivacionais e de agressividade para a competição mais baixos que as europeias.

Bénéfice et al.(9), num outro estudo realizado com 139 rapazes e raparigas comparou a coordenação e a performance motoras de crianças Senegalesas com diferentes histórias nutricionais e determinou a influência das dimensões corporais na variância da coordenação e performance motoras. Para o efeito, foram utilizados os critérios antropométricos para classificação nutricional para dividir a amostra em 3 grupos nomeadamente, um grupo com história clínica de algum estado de depressão nutricional, um segundo com história de desnutrição severa e um terceiro considerado nutricionalmente normal. Além das variáveis somáticas os sujeitos realizaram 6 testes de coordenação motora e 5 testes motores. No cômputo geral, o grupo de crianças bem nutridas obteve melhores performances na maioria dos testes comparativamente aos grupos com problemas nutricionais. As dimensões corporais explicaram uma significativa parte da variância da aptidão motora, tendo sido a altura a revelar-se como melhor preditor. Todavia, depois de remover o efeito da idade e do tamanho corporal, as diferenças entre os três gru- pos nutricionais desapareceram na performance motora, ainda que tenham persistido em alguns testes coordenativos. Os autores concluíram que a má nutrição per se, conjugada com a pequenez das dimensões corporais, atraso no crescimento e condições precárias são factores que afectam negativamente a performance motora e coordenativa de crianças em áreas em vias de desenvolvimento no mundo, e que as diferenças encontradas entre os grupos nutricionais na performance motora e coordenativa eram fundamentalmente explicadas pelas diferenças no tamanho.

Socorrendo-se da equação alométrica fundamental Corlett(16) investigou, em 240 crianças de ambos os sexos dos 7 aos 12 anos de idade (120 de cada género), os efeitos das variáveis dimensionais nas provas de força estática, impulsão vertical e longitudinal e na prova de corrida. As diferenças encontradas entre os expoentes dimensionais teóricos e empíricos da amostra revelaram ausência do pressuposto de similaridade geométrica, a qual era, segundo o autor, explicada pela ausência de variação substancial na composição corporal. Por outro lado, os resultados sugeriram, de forma algo explícita, a presença de diferenças manipulativas na realização dos testes, facto que parece constituir a substância interpretativa do dimorfismo sexual que os resultados do estudo revelaram.

As questões alométricas ligadas à expressão diferencial da aptidão física, também foram investigadas por Prista et al.(55), num estudo realizado em 593 crianças moçambicanas de ambos os sexos, com idades compreendidas entre os 8 e os 15 anos (rapazes, $n=$ 276; raparigas, $n=317$ ). Para além do peso e da estatura, foram avaliadas a força abdominal e de preensão, a agil idade e a resistência cárdio-respi ratória. Constituía propósito do estudo, verificar se os expoentes alométricos eram equivalentes aos postulados pela teoria dimensional, por forma a tornar equilibrada a comparação da performance entre os sexos. Os valores empíricos encontrados não confirmaram os da teoria dimensional, o que pareceu traduzir aspectos peculiares do crescimento linear e ponderal das crianças e jovens de Moçambique. Benéfice e Malina(7) pesquisaram a relação entre as características antropométricas e a performance motora, bem como a influência relativa das dimen- 
sões e composição corporais na variabilidade da performance motora em 348 crianças, classificadas como moderadamente subnutridas e com idades compreendidas entre os 5 e os 13 anos. As medidas compreenderam peso, altura, perímetros, pregas de adi posidade, velocidade, arremesso de bola, impulsão horizontal sem corrida preparatória e força de preensão. A altura e o peso explicaram $30-50 \%$ da variância na performance das crianças com menos de 10 anos, enquanto que nas com mais de 10 anos, o peso explicou cerca de $10-25 \%$ da variância. Por outro lado, os indicadores da composição corporal revelaram uma limitada contribuição na variância da performance motora. Contudo, foi possível observar que a gordura corporal afectava negativamente a performance motora das raparigas com idade superior a 10 anos. Os autores consideraram que os resultados não permitiam esclarecer a associação entre o estado de "stunted" e "wasted" e a relativamente reduzida performance nos testes, sublinhando, como em outros trabal hos, a ausência de controlo sobre o determinismo cultural na prestação dos testes. Pieterse et al.(49) estudaram a influência do tamanho corporal na capacidade de produção de força em indivíduos adultos investigando a associação entre o estatuto nutricional e a força de preensão em 828 refugiados Ruandeses adultos de ambos os sexos e com idades compreendidas entre os 50 e os 92 anos. As variáveis avaliadas consistiram no peso, altura, perímetro braquial, prega adiposa tricipital e dinamometria manual. Os resultados revelaram valores médios de força de preensão dos homens mais elevados em relação às mulheres $(30.3 \pm 6.7 \mathrm{Kg}$ vs $22.3 \pm 5.1 \mathrm{Kg} ; \mathrm{p}<0.001$ ), e uma tendência de diminuição ao longo da idade. A força de preensão manual correlacionou-se positivamente com o índice de massa corporal (homens, $r=0.26$; mulheres, $r=$ 0.16 ) e com o perímetro braquial (homens, $r=0.41$; mulheres, $r=0.26$ ). $O$ índice de massa corporal revelou-se como uma variável contribuinte para a variação da força de preensão, mesmo depois de controlar o efeito do género sexual, idade e altura. Considerando a característica da população estuda$\mathrm{da}$, os autores verificaram que o estatuto nutricional se associava de forma independente da capacidade de produzir força de preensão.
Dois estudos realizados em Moçambique revelam uma inqui etação em torno da generalização dos critérios antropométricos de classificação nutricional e al ertam para a necessidade de validação transcultural dos mesmos $(53,58)$. No primeiro estudo foi utilizada a aptidão física, medida por um conjunto de testes da bateria da A A H PERD (1) e EUROFIT (23), e a actividade física habitual, medida por questionário. As medidas foram real izadas em 316 crianças e jovens em idade escolar da Cidade de Maputo, as quais foram posteriormente classificadas nutricional mente de acordo com as normas da OMS(48). Não obstante, e de acordo com os critérios referenciados $46.2 \%$ da amostra ter demonstrado algum sinal de malnutrição, a aptidão física só se diferenciou nas tarefas em que a massa muscular era determinante. No caso da actividade física, nenhum efeito do estatuto nutricional pôde ser observado. Foi assim constatado que as diferenças entre os grupos só se revelavam quando a estatura corporal determinava a performance. $\mathrm{Na}$ continuidade deste estudo, Prista et al.(58) repetiram o procedimento com uma amostra substancialmente maior ( $n=2316$ ), ampliando o escalão etário (6-18 anos) e introduzindo, para além da aptidão física e actividade física, variáveis do fórum clínico. Os critérios de classificação nutricional foram actualizados de acordo com a OMS(69). Pretendiam os autores testar com mais robustez a validade dos critérios para a população escolar de Maputo. Não obstante o número considerável de variáveis, não foi, de novo, possível encontrar relevância nos critérios que classificam subnutrição, embora os autores tenham constatado validade nos valores de corte para definição de sobrepeso e obesidade.

Pode-se assim dizer que a pesquisa em torno da aptidão física e estatura em África tem dado uma importante contribuição no esclarecimento da relevância do tamanho corporal para a performance, e através da classificação nutricional, do estado de saúde. Não obstante a grande polémica em torno do tema, da revisão da literatura Africana, emergem evidências que permitem concluir que, (1) uma grande parte do stress nutricional se repercute na estatura dos sujeitos, a qual por sua vez tem uma influência determinante na performance, (2) que as diferenças de performance entre grupos nutricionais quase que exclusivamente se explicam pelas diferenças estatu- 
rais e (3) que a relevância dos critérios de classificação nutricional do ponto de vista da aptidão física desaparece, quando as tarefas não dependem do tamanho corporal e/ ou as diferenças estaturais deixam de existir. $O$ debate sobre as vantagens e desvantagens de ser pequeno em torno da saúde e produtividade mantém-se assim em aberto.

\section{APTIDÃO FÍSICA E ESTATUTO SÓCIO-ECONÓMICO}

Em Africa, o estudo da interacção hereditariedadeambiente na interpretação da variação observada num dado fenótipo, como seja a aptidão física dos indivíduos, encontra condições simultaneamente privilegiadas, porém de acrescida complexidade. A enorme variação cultural e a grande clivagem social, conjugadas com uma extrema diversidade biológica dão origem a ambientes extremamente ricos, e por isso complexos, em factores que co-determinam as características humanas. A potencializar, a urbanização crescente provoca o desabrochar de grandes aglomerados de populações que misturam hábitos e estágios de desenvolvimento, potencializados pelo chamado fenómeno da "globalização".

Esta condição tem sido explorada pelos investigadores que procuram explicar a variabilidade na aptidão física através de abordagens metodológicas como seja, (1) pela comparação de grupos étnicos e raciais, (2) pela comparação entre populações urbanas e rurais, (3) e pela comparação entre grupos classificados por critérios sócio-económicos e (4) a avaliação da tendência secular.

\section{Comparação por grupos étnicos}

Goslin e Burden(29) investigaram a aptidão física de 222 crianças sul-africanas de ambos os sexos em idade escolar (brancas, $n=98$, mestiças, $n=92$; negras, $n=32$ ) pertencentes a grupos culturais e sócio-económi cos distintos. Para além do peso e da al tura, avaliaram a flexibilidade, a agilidade, a força, o equilíbrio, a potência anaeróbia e aeróbia, a resistência muscular e cardiorespi ratória e a composição corporal através do somatório de pregas adiposas.

As crianças brancas apresentaram melhores valores de peso e altura em relação aos demais grupos, mas apesar disso as crianças negras obtiveram melhores resultados ao nível da força. Os resultados da estimativa de $\mathrm{VO}_{2}$ máx evidenciaram um maior poten- cial aeróbio $(p<0.05)$ das crianças brancas (a61 $\mathrm{ml} / \mathrm{kg} / \mathrm{min}$ ) em relação às mestiças ( $\mathrm{ml} / \mathrm{kg} / \mathrm{min}$ ) e negras ( rel ação àquelas. Os autores encontraram grandes dificuldades para explicar os resultados considerando que a interacção do factor racial com estados sócio-económicos e culturais distintos, como sejam hábitos nutricionais e padrões da actividade física habitual, poderiam influenciar determinantemente a prestação nos testes.

Também na Africa do Sul, Badenhorst et al.(3) investigaram 22 rapazes negros dos 9 aos 15 anos residentes em zonas rurais, comparando os resultados com seus compatriotas sócio-economicamente privilegiados. As variáveis em estudo incluíram peso, altura, pregas de adiposidade, $\mathrm{VO}_{2}$ máx, a actividade física habitual e o estatuto nutricional. Os resultados revelaram uma ingestão calórica em Quilojoules na ordem dos 37-41\% inferior em relação à quantidade diária recomendada; uma ingestão satisfatória de proteínas; baixa percentagem de gordura corporal, sem que no entanto tivessem sido encontradas situações de "stunting" ou "wasting". Não obstante o défice em aporte nutricional, os valores de $\mathrm{VO}_{2}$ máx encontrados (9-10 anos $=49.8 \pm 3.4 \mathrm{ml} / \mathrm{kg} / \mathrm{min}$; 11 12 anos $=48.4 \pm 3.1 \mathrm{ml} / \mathrm{kg} / \mathrm{min}$ e $13-14$ anos $=$ $50.6 \pm 3.8 \mathrm{ml} / \mathrm{kg} / \mathrm{min}$ ) eram comparáveis aos encontrados por outros autores para crianças da mesma idade. Uma capacidade adaptativa destas crianças ao "stress" ambiental e às condições nutricionais adversas foi apontada pelos autores para explicar estes resultados.

\section{Comparação cidade-campo}

Na Tanzânia, Davies et al.(20) avaliaram e compararam a composição corporal e a aptidão aeróbia, avaliada através de um teste de esforço submaximal e maximal em cicloergómetro em 94 jovens adultos de ambos os sexos residentes em Dar-es-Salamm. Os resultados encontrados foram comparados com dados provenientes de 48 homens e 7 mulheres europeus. No plano somático, os resultados dessa comparação indicaram que os africanos eram mais leves e mais baixos que os europeus, possuíam menos gordura corporal, menos massa isenta de gordura e menor volume da perna. Em relação à potência aeróbia os europeus apresentavam, em ambos os 
sexos, valores absolutos de $\mathrm{VO}_{2}$ máx superiores aos africanos (homens $=3.48 \pm 0.46$ vs $2.76 \pm 0.39$ L. $\mathrm{min}^{-}$ 1; mulheres $=2.45 \pm 0.31$ vs $2.00 \pm 0.24$ L. $\mathrm{min}^{-1}$ ).

Esta superioridade, ainda que atenuada, mantinha-se mesmo quando o $\mathrm{VO}_{2}$ máx era rel ativizado à massa isenta de gordura.

Resultados divergentes foram encontrados por Wyndham (70) numa pesquisa em que avaliou a influência do peso corporal, idade, género e da altitude sobre a capacidade de trabal ho $\left(\mathrm{VO}_{2}\right.$ máx $)$ em 906 sujeitos Bantus, com valores médios de idade de 32-40 anos, provenientes de duas províncias da África do Sul, nomeadamente Venda (zona rural, $\mathrm{n}=$ 241; zona urbana, $n=240$ ) e Pedi (zona rural, $n=$ 202; zona urbana, $n=223$ ). Os principais resultados deram conta de que os sujeitos Bantus da zona rural apresentavam valores mais baixos de peso (Venda $=56.7$ vs $64.1 \mathrm{Kg}$; Pedi $=56.2$ vs $60.6 \mathrm{Kg}$ ) e de $\mathrm{VO}_{2}$ máx (Venda $=39.9$ vs $40.5 \mathrm{ml} / \mathrm{kg} / \mathrm{min}$; Pedi $=37.6 \mathrm{vs} 41.9 \mathrm{ml} / \mathrm{kg} / \mathrm{min}$ ) em relação aos da zona urbana. Os valores de $\mathrm{VO}_{2}$ máx de sujeitos sul-africanos Bantus da zona urbana eram similares aos encontrados em trabal hadores noruegueses da indústria e em mineiros brancos do intervalo etário de 30-39 anos. Contudo, os valores apresentados quer pelos sujeitos Bantus da zona urbana, quer pelos da zona rural testemunhavam uma fraca capacidade de trabalho em relação aos resultados médios disponíveis na literatura referentes aos atletas e sujeitos activos do mesmo intervalo etário. Procedendo igualmente a uma comparação entre etnias, Austin et al.(2), compararam a capacidade de trabal ho e a morfologia de dois grupos étnicos da região ocidental do Zaire, numa amostra de 169 homens e mulheres de idades compreendi das entre os 18 e os 40 anos pertencentes às etnias $\mathrm{N}$ tomba e Twa. As medidas incluíram indicadores somáticos e a potência máxima aeróbia. A etnia N tomba apresentou médias mais elevadas de peso (homens, $58.2 \pm 7.97 \mathrm{~kg}$ vs $47.5 \pm 5.56 \mathrm{Kg}, \mathrm{p}<0.01$; mulheres, $48.0 \pm 7.04 \mathrm{~kg}$ vs $44.1 \pm 7.06 \mathrm{Kg}, \mathrm{p}<0.05)$ e altura (homens, $168.46 \pm 6.16 \mathrm{~cm}$ vs $159.5 \pm 5.78 \mathrm{~cm}$, $\mathrm{p}<0.01$; mulheres, $155.71 \pm 4.73 \mathrm{~cm}$ vs $153.10 \pm 4.76 \mathrm{~cm}, p<0.05)$, enquanto que a composição corporal se revelou idêntica. Em termos de $\mathrm{VO}_{2}$ máx, a etnia Ntomba apresentou valores médios absolutos mais elevados, que quando relativizados ao peso corporal o deixavam de ser.
Corlett(18) avaliou e comparou a força de preensão em crianças do Botswana de ambos os sexos ( $\mathrm{n}=$ 612; idade: 7-12 anos) provenientes de dois meios distintos, sendo 240 do meio urbano. A análise evidenciou, para além do comum efeito significativo da idade e género sexual, que as crianças urbanas superavam as do meio rural em ambos os sexos, mesmo após o ajustamento dimensional para diferenças de tamanho, sendo as diferenças mais acentuadas nas idades mais baixas e tendentes a diminuírem ao longo da idade. Segundo este autor, os resultados da força de preensão encontrados eram meramente uma expressão funcional da vantagem anatómica resultante das melhores condições nutricionais que as crianças do meio urbano têm relativamente às do meio rural.

Ainda na Africa do Sul, Henneberg e Louw(33) investigaram os padrões de crescimento somático e da aptidão física em crianças do meio urbano e rural da cidade do Cabo e da região de Klein Karoo. Numa amostra de 3748 sujeitos de ambos os sexos dos 5 aos 19 anos, e utilizando testes de velocidade de reacção e preensão manual, os autores observaram superioridade das crianças e jovens de estatuto socio-económico mais elevado, uma vez mais associada a uma mai or estatura, também aqui mais pronunciada nas idades mais jovens. Resultados concordantes foram encontrados por Henneberg et al.(34), ao investigarem a relação entre força muscular estática e o ESE de crianças e jovens negros da África do Sul de ambos os sexos dos 6 aos 18 anos (rapazes, $n$ $=1704$; raparigas, $n=1956$ ). $A$ amostra foi aval iada na força de preensão manual, prega adiposa tricipital e velocidade de reacção. Os resultados revel aram uma nítida vantagem na produção de força muscular dos sujeitos de ESE mais elevado. Os valores médios superiores foram mais evidentes a partir da puberdade, mesmo quando ajustados à área de secção transversal do músculo.

Comparação pela região e tipo de escola A escolha da escola como critério de dassificação do estatuto sócio-económico tem constituído um recurso alternativo à grande dificuldade de sistematizar este critério na realidade Africana. Utilizando este procedimento, Guesquière e Eeckles(30) pesquisaram os padrões de aptidão física em crianças do ensino 
primário da cidade de Kinshasa, estratificadas em função ao tipo de escola frequentada. Os resultados do estudo evidenciaram que a grandeza estatural dos estudantes das escolas privilegiadas expressava uma vantagem em termos absolutos. Todavia, quando ponderados em função do peso corporal a vantagem desaparecia, e as crianças provenientes da escola pública, não obstante a sua pequenez estatural e maior incidência de parasitêmias, apresentavam performances similares e mesmo superiores em relação aos restantes. De acordo com estes autores, as condições adversas da vida no meio suburbano afecta menos a aptidão física do que o desenvolvimento físico e, por outro lado, o incremento de peso nos sujeitos desfavorecidos processa-se através do aumento da massa muscular, o que em termos relativos, se traduziria em vantagem na produção de trabal ho.

A influência do estatuto sócio-económico nos valores da aptidão física foi estudada em Moçambique com o recurso a idêntico procedimento(52). Os autores classificaram os grupos sócio-económicos em função de escolas e de acordo com regiões da Cidade. Foram envolvidas um total de 593 crianças e jovens de ambos os sexos dos 8 aos 15 anos. As provas de aptidão física realizadas incluíram flexibilidade, força de resistência abdominal, força de preensão, agilidade e resistência cardiorespiratória, tendo os resultados sido comparados em função dos grupos sócio-económicos. Controlando o efeito da idade e do sexo, as crianças e jovens social mente mais desfavorecidos apresentaram prestações significativamente mais elevadas nos testes de flexibilidade e resistência cardiorespiratória. Apesar de uma acentuada diminuição de estatura relativamente aos mais privilegiados, a força de preensão manual não foi diferente entre os grupos, ainda que a resistência abdominal tenha sido mais elevada nos grupos social mente favorecidos. Utilizando a comparação da actividade física habitual dos grupos em estudo, avaliada por questionário validado para esta população(56), os resultados sugerem que os grupos desfavorecidos, apesar de apresentarem sinais somáticos de sequelas nutricionais, são fisicamente mais aptos em função de um perfil de actividades de sobrevivência e jogos activos ao ar livre que lhes conferem um dispêndio energético e vivência motora consi deravelmente intensa. Para os autores, o contraditório resultado no teste de sit-ups poderá estar associado a questões culturais, já que sendo um movimento alheio à cultura local, é tecnicamente mais vivenciado por populações que vivem em contacto com a "cultura do mundo desenvolvido".

\section{Tendência secular}

As repercussões da passagem repentina de Moçambique de uma situação de guerra e de miséria para uma situação de paz e de economia de mercado constituiu uma ocasião única para avaliar os efeitos ambientais em diferentes fenótipos. Foi neste contexto que Saranga et al.(59), enquadrados na investigação dos aspectos relativos à designada "tendência secular", investigaram as mudanças nos níveis de aptidão física na Cidade de Maputo, comparando dois estudos realizados nas mesmas escolas e com procedimentos idênticos, respectivamente nos anos de 1992 e 1999. As amostras envolveram, na totalidade, 2749 rapazes e raparigas em idade escolar. A aptidão física foi avaliada através das provas seleccionadas dos protocolos da AAH PERD (1) e EUROFIT(23). A generalidade dos resultados do estudo permitiu constatar uma abrupta redução do valor físico da população escolar de 1992 para 1999, e que os autores advogam se dever a uma drástica mudança de hábitos de actividade e nutricionais confirmadas pela aplicação, em ambos os estudos, de um questionário de avaliação da actividade física habitual. Esta redução de hábitos de actividade e performance física é igualmente sugerida como responsável pelo aumento da prevalência de factores de risco de doença cardiovascular observada na mesma população no mesmo intervalo temporal (19).

Da investigação publicada sobre estudos em África que versam a influência do estatuto socio-económico na aptidão física das populações, infere-se um acentuado défice metodológico no que respeita à classificação dos sujeitos. As estratégias adoptadas, se bem que operativamente satisfatórias apresentam pouca robustez. Assumindo esta limitação, os estudos revistos além de escassos, apresentam resultados díspares que podem também advir da característica dinâmica e contextual da aptidão física. Há contudo um primado comum que gira em torno do efeito da estatura corporal na performance. Com efeito, parece ser consensual que, em determinadas tarefas, a infe- 
rioridade estatural constitui uma desvantagem e sendo esta produto de uma condi ção sócio-económica desvantajosa, se poderá dizer que a aptidão é negativamente influenciada pela condição social. Contudo, o facto destas crianças estarem expostas a um meio higiénico-nutricional desfavorável, e ainda assim, apresentarem valores de aptidão semel hantes e por vezes superiores aos de outras mais favorecidas, parece efectivamente reflectir, uma plasticidade adaptativa na interacção com o seu meio envolvente. Neste capítulo, a literatura reflecte inqui etação e incerteza relativamente à polémica da capacidade de trabal ho absoluta e relativa e sua real importância para os países Africanos.

\section{INFECÇÕES PARASITÁRIAS E APTIDÃO FÍSICA}

África é um continente com uma expressiva prevalência de doenças infecto-contagiosas. As publicações sobre o seu efeito na aptidão funcional em Africa limitam-se praticamente à bilharziose (Schistosomiasis haematobium). Os primeiros estudos levados a efeito nesta vertente pareciam sustentar a ideia de que a bilharziose não tinha nenhum efeito negativo sobre a capacidade de trabal ho(15, 21, 66). Walker et al.(66) avaliaram o efeito da bilharziose sobre a capaci dade física em 329 crianças sul-africanas de ambos os sexos (rapazes, $n=156$; raparigas, $\mathrm{n}=173$ ) com idades compreendidas entre os 14 e os 15 anos. A amostra compreendia dois grupos, nomeadamente o grupo de infectados e o grupo de não infectados. Foram usadas como variáveis o peso, a al tura, as pregas adiposas tricipital e subescapular e o teste de 12 minutos de marcha/ corrida. Os resultados encontrados evidenciaram uma semel hança estatística entre as médias dos dois grupos, tanto a nível das medidas somáticas como a nível da performance de corrida. Estes autores assumi ram que no contexto das crianças Bantus estudadas, a bilharziose não afectava a performance de corrida, advogando que, outros factores como a motivação, a maior actividade física habitual que caracteriza as crianças residentes em zona rural, assim como o baixo peso em função da idade seriam possíveis agentes que explicavam os resultados. Mais tarde, Davies(21) e Collins et al.(15) também encontraram resultados que corroboravam os do estudo anterior, ao não encontrar qualquer efeito negativo da bilharziose na resposta cardiorespiratória ao exercício em crianças de Tanzânia e na capaci dade produtiva em cortadores de cana do Sudão, respectivamente.

De modo particularmente interessante, Kvalsvig e Becker(36) ao pesquisarem o comportamento de crianças infectadas na África do Sul, constataram que eram mais sociáveis e activas nos jogos relativamente às crianças não infectadas, e que gostavam, inclusivamente, de nadar e brincar em lagoas altamente contaminadas, apontando este facto como um dos vectores de contaminação daquelas crianças. Outros estudos apresentam resultados contraditórios, levando al guns autores a considerem que a carga parasitária, i.e., a intensidade de infecção, seja determinante na detecção de efeitos negativos na performance motora. Nesta linha, Stephenson et al.(62) lograram demonstrar, num estudo realizado no Quénia, que altos índices de infecção de bilharziose prejudicavam a aptidão física, para além de causar perda de ferro por via urinária e, consequentemente, anemia. Por outro lado, Ndamba(44) mostrou, no Zimbabwé, que crianças não infectadas e crianças fortemente infectadas depois de tratamento evidenciavam uma melhor resistência cardiorespiratória em relação às crianças infectadas antes de tratamento. Mais tarde, estes resultados foram confirmados no Quénia, onde crianças infectadas exibiram, após o tratamento, não só melhores resultados no teste de degrau de Harvard(37), como também evidenciaram um maior apetite, melhores taxas de crescimento e revelaram-se mais activas(64).

Outros autores têm envidado esforços no sentido de determinar o efeito do tratamento da bilharziose sobre a aptidão física. Nesta perspectiva, Stephenson et al.(63) aplicaram o tratamento com al bendazole em 33 rapazes quenianos com idades compreendidas entre os 6-12 anos, infectados com hookworm, Trichuris trichiura e A scaris lumbricoides, e aplicaram o teste de degrau de Harvad modificado para determinar valores do esforço submaximal de crianças. Sete semanas após o tratamento, o grupo de al bendazole apresentou uma redução de prevalência e de intensidade de infecção de H ookw orm e de A . Lumbricoides na ordem de $80 \%$ e $100 \%$, contra $17 \%$ e $20 \%$ de aumento verificados no grupo de placebo, respectivamente. Contudo, tanto a prevalência quanto a intensidade de infecção com $\mathrm{T}$. trichiura não se alterou. 
Cerca de $78 \%$ das crianças tratadas melhoraram a aptidão cardiorespiratória, contra 33\% dos rapazes do grupo de placebo. Este estudo permitiu verificar que um tratamento de crianças com desvantagens nutricionais e infectadas com H ookw orm e A scaris lumbricoides, através de uma dose oral simples de albendazole, pode melhorar a sua aptidão física sete semanas após o tratamento.

Num outro estudo, usando o mesmo teste de degrau acima descrito, Stephenson et al.(64) determinaram, em 53 rapazes Quenianos infectados com $\mathrm{H}$ ookw orm, Trichuris e A scaris, o efeito de tratamento com uma simples dose de 600-mg de al bendazole sobre a aptidão física. Quatro meses após o tratamento, o grupo experimental apresentou uma redução de prevalência e de intensi dade de infecção de $\mathrm{H}$ ookw orm, A .

Lumbricoides e Trichuris na ordem de $81 \%$, 99\% e 39\%, contra $31 \%, 27 \%$ e $1 \%$ de aumentos verificados no grupo de controlo, respectivamente. Para além de uma significativa melhoria nas variáveis somáticas, o grupo experimental evidenciou significativas melhorias na aptidão cardiorespiratória.

Numa outra pesquisa, desta feita em adultos, $\mathrm{N}$ damba et al.(45) investigaram 497 cortadores de cana-de-açúcar, dos quais 287 infectados com Schistosoma M ansoni. Ao pretenderem avaliar o efeito do estado infeccioso na capaci dade física e produtividade, os autores socorreram-se do teste de degrau de Harvard e da medida da quantidade de cana cortada num dado intervalo de tempo. A pós dezasseis semanas de tratamento, a aptidão física dos trabal hadores infectados melhorou em $4.3 \%$ e a produtividade em $16.6 \%$. A aptidão física e a produtividade dos não infectados também mel horou durante o mesmo período, mas sem significância estatística, o que pareceu dever-se ao exercício físico ocupacional. Este estudo permitiu observar que o tratamento de bilharziose assegura a melhoria tanto da aptidão física como da produtividade e que existe uma correlação entre a intensidade de infecção e os níveis de aptidão física e de produtividade pré-tratamento. Em suma, os estudos realizados em África, centrados na aval iação e interpretação do efeito das doenças infecto-contagiosas sobre a aptidão física, crescimento e produtividade, sugerem que (1) tomando em consideração a intensidade de infecção, a presença de parasitas tem influência negativa no desempe- nho em testes físicos; (2) a velocidade de crescimento é, também, negativamente influenciada pela acção dos parasitas e (3) os efeitos negativos desses parasitas no crescimento e na aptidão física, são reversíveis com o tratamento adequado. Por outro lado, parece incontroverso que os estudos do impacto de doenças infecto-contagiosas, condições higiénicosanitárias e nutricionais sobre a aptidão física em África têm que levar em conta a grande complexidade do assunto que obriga a equacionar factores como as diferenças nos padrões de crescimento, as deficiências nutricionais, a anemia e a acção isolada ou concomitante dos agentes infeccioso-parasitários.

\section{ACTIVIDADE FÍSICA}

Os estudos dos padrões de actividade física em populações africanas revestem-se de particular importância, já que as actividades de subsistência da mai or parte da população deste continente são de demanda energética significativa. Sendo um continente com uma taxa de urbanização muito baixa, os estudos consultados procuram traduzir os níveis de actividade física dos africanos em contextos rurais e urbanos, ou procuram contrastar as duas realidades. Em ordem a determinar até que ponto baixos níveis de dispêndio energético no trabal ho e no lazer poderiam contribuir para elevadas taxas de prevalência de doença cardiovascular, Noakes et al.(47) avaliaram a actividade física e dispêndio energético no trabal ho e lazer em 7188 sul-africanos "caucasianos" de ambos os sexos com idades que variavam entre os 15 e os 64 anos provenientes de três zonas rurais. Em todas as idades, e em ambos os sexos, menos de $1 \%$ dos sujeitos avaliados executavam tarefas que requeriam taxas elevadas de dispêndio energético. A partir dos 24 anos de idade, registou-se um decréscimo acentuado da participação em actividades moderadas e vigorosas durante o tempo de lazer. Acima dos 44 anos, menos de $26 \%$ dos homens e menos de $16 \%$ das mulheres excediam a quantidade de $8400 \mathrm{Kj}$ semanais durante o tempo de lazer, quantidade recomendada como limiar de protecção coronária. Utilizando este critério, os autores consideraram que a população estudada era caracterizada por níveis baixos de actividade física ocupacional e de lazer. Bénéfice ${ }^{(6)}$ examinou 100 crianças Senegalesas com idades compreendidas entre os 10 e os 13 anos com o 
propósito de analisar os efeitos da má nutrição crónica na funcional idade e nos padrões de actividade física. Para além dos indicadores antropométricos, a actividade física foi avaliada através da monitorização da frequência cardíaca minuto a minuto durante 6 horas. A funcionalidade foi avaliada por meio de um teste submaximal realizado em subida e descida dum degrau e de quatro testes motores. Os resultados permitiram constatar que dois terços da amostra apresentavam valores de peso abaixo de -1 DP das normas de WHO/NCHS referentes àquelas idades. Quando comparadas com o com os seus parceiros de países desenvolvidos, as crianças estudadas evidenciaram níveis inferiores de actividade física, bem como resultados inferiores em todos os testes de aptidão física. Ao agrupar as crianças com base no défice do peso em função da idade verificou-se que o grupo classificado de mal nutrido apresentava índices de aptidão funcional bastante inferiores, embora nenhuma diferença em relação à intensidade da actividade física tenha sido encontrada. Para o autor, estes resultados testemunham claramente o efeito negativo da má nutrição na performance motora das crianças.

Sparling et al.(60) investigaram a associação entre a actividade física e os factores de risco de doença cardiovascular em 212 sujeitos negros sul-africanos de sexo masculino, com idades compreendidas entre os 25 e os 64 anos. As variáveis estudadas consistiram na altura, peso, perímetro braquial, pressão arterial, colesterol total, HDL-colesterol e actividade física, que foi medida através de questionário-entrevista. Os resultados indicaram que $43 \%$ dos sujeitos da amostra tinham empregos que requeriam uma actividade física moderada a vigorosa, e que os perfis de concentração de lípidos e de pressão arterial mais favoráveis se associavam a níveis baixos a moderados de exercício físico habitual. Na perspectiva dos autores, estes resultados parecem atribuir à actividade física habitual e à ausência de um estilo de vida sedentária um papel explicativo da baixa taxa de morbilidade e mortalidade por doença cardiovascular na população negra sul-africana.

Bénéfice e Cames(8) estudaram os padrões de actividade física e as estimativas diárias de dispêndio energético em 40 raparigas adolescentes senegalesas rurais com $13.5 \pm 0.5$ anos de idade. A actividade física foi avaliada através de acelerómetros durante qua- tro dias consecutivos e de uma observação di recta durante dois dias consecutivos. As raparigas participantes no estudo foram seguidas durante as épocas seca $(n=40)$ e chuvosa $(n=30)$. Com os coeficientes de correlação intraclasse a evidenciarem uma fiabilidade aceitável de registo dos movimentos $(r=0.71)$, foi possível observar uma relação linear entre a quantidade de movimentos registados e os valores directamente observados. Os níveis de actividade física preditos foram considerados elevados

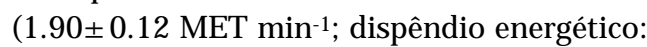
$9.03 \pm 0.77 \mathrm{MJ}$ ). Durante o dia a quantidade de movimentos registados foi mais elevada na época chuvosa que na época seca. Foi observada uma depressão do estado nutricional durante a época chuvosa em toda a amostra. Constatou-se que a estimativa de dispêndio energético associado à actividade das raparigas adolescentes Senegalesas era superior à das adolescentes urbanas dos países desenvolvidos, porém bastante semelhante à de adol escentes de zonas rurais dos mesmos países.

No Senegal encontramos quatro estudos transversais da actividade física efectuados sobre várias subamostras de um estudo longitudinal do crescimento durante a puberdade realizado com raparigas adolescentes rurais dos 13.4 aos 15.3 anos de idade. $O$ primeiro(26) pretendia testar a hipótese de que os níveis de actividade física de adolescentes rurais Senegalesas diferiam em função da zona geográfica e das condições de vida, e que essas diferenças tinham repercussões negativas no crescimento e maturação daquele extracto populacional. Para o efeito avaliaram a actividade física habitual de 80 raparigas divididas em dois grupos, sendo um de migrantes $(n=$ 40), constituído por raparigas que saíram do campo para a cidade e o outro $(n=40)$ constituído por raparigas que permaneceram no campo para ajudar as famílias nas tarefas domésticas e de agricultura. As variáveis de estudo incluíram peso, altura, pregas de adi posidade, maturação sexual, estado nutricional e actividade física. O estado nutricional foi avaliado com base em índices antropométricos, o estatuto maturacional de acordo com estágio de desenvolvimento da mama e da idade de menarca, enquanto que a intensidade e os padrões de actividade física foram avaliadas através de acelerómetros e de um questionário para avaliar a natureza das actividades 
diárias bem como a respectiva frequência. Os resultados revelaram que as adolescentes estudadas eram mais baixas, mais magras e com um atraso maturacional em relação às raparigas dos países desenvolvidos do mesmo intervalo etário. As raparigas migrantes pesavam $3.5 \mathrm{Kg}$ a mais em relação às raparigas rurais, apresentando maiores valores de gordura corporal. A fiabilidade de registo dos acelerómetros, avaliada por comparação de dois dias seguidos, foi excelente $(r=0.90)$. As raparigas migrantes evidenciaram valores médios diários de actividade física mais elevados em relação às raparigas rurais, e despenderam mais tempo em actividades moderadas a intensas ( $9.3 \mathrm{~h} / 24 \mathrm{~h}$ vs $6.1 \mathrm{~h} / 24 \mathrm{~h})$. As raparigas rurais dormiram ou estiveram inactivas por um período mais longo ( $7.6 \mathrm{~h} / 24 \mathrm{~h}$ vs $6.3 \mathrm{~h} / 24 \mathrm{~h})$ e descansaram mais $(2.1 \mathrm{~h} / 24 \mathrm{~h}$ vs $0.8 \mathrm{~h} / 24 \mathrm{~h})$. Os resultados do estudo da influência do estatuto maturacional na actividade física mostraram que as raparigas migrantes, com atraso maturacional eram mais activas, enquanto que o inverso foi observado no grupo das raparigas rurais. $O$ estado nutricional das migrantes foi melhor apesar da maior carga de trabal ho. Segundo os autores, as diferenças encontradas podem ser explicadas pelas diferentes condições de vida e de aporte nutricional entre o campo e a cidade. O segundo estudo(10), foi realizado ao longo de três anos com 40 raparigas da mesma amostra, com o objectivo de examinar os níveis de actividade física e a evolução do dispêndio energético. Para além do peso e da altura, as variáveis do estudo compreenderam pregas de adiposidade subcutâneas, perímetros, estatuto maturacional, estado nutricional e a actividade física avaliada quantitativamente através de acelerómetros. $\mathrm{O}$ grupo de adolescentes estudadas evidenciou níveis elevados de dispêndio energético e níveis de actividade física diária que variaram entre $1.70 \mathrm{e}$ 1.85 METs. Os níveis de actividade física registaram uma redução ao longo do crescimento, tendo sido entre o primeiro e o terceiro ano que se observaram alterações no sentido negativo. Os resultados de análise de regressão "stepwise" permitiram constatar que a estatura se correlacionava negativamente com o tempo total de actividade, enquanto que o índice de massa corporal se correlacionou positivamente com esta variável. O estado pubertário e a gordura corporal não se revelaram bons preditores de níveis de actividade física. A contribuição destas adolescentes nas tarefas quotidianas domésticas foi bastante considerável, chegando a despender mais de três horas e meia por dia neste tipo de tarefas.

No terceiro estudo(11), os autores pretendiam analisar a influência da idade, do estatuto maturacional e da composição corporal nos níveis de actividade física na mesma sub-amostra. Os registos da actividade física foram feitos durante quatro dias no primeiro ano de avaliação (1997) e durante três dias nos dois anos de avaliação subsequentes ( 1998 e 1999). Entre as constatações mais rel evantes destaca-se o facto das raparigas que frequentavam a escola terem se revelado menos activas em relação às que não frequentavam a escola e das raparigas de estado maturacional mais avançado apresentarem maiores níveis de actividade física durante a noite. O quarto estudo(27), que deriva de uma abordagem longitudinal do primeiro estudo, analisou a influência da migração urbana na actividade física, no estado nutricional e no crescimento numa amostra constituída por 80 adolescentes com uma média de idade de 14.4 40.5 anos. A sub-amostra foi avaliada quantitativamente em actividade física durante três dias consecutivos através de acelerómetros e qualitativamente por meio de questionário; o estatuto maturacional foi avaliado com base no desenvolvimento da mama e da ocorrência da menarca; enquanto que o crescimento somático e o estado nutricional foram avaliados através de índices antropométricos. A mesma sub-amostra foi dividida em dois grupos, nomeadamente grupo de não-migrantes $(n=40)$, constituído por raparigas que permaneceram no campo e 0 grupo de migrantes $(n=40)$, constituído por raparigas que migraram para a cidade em busca de trabaIho. As raparigas pertencentes ao grupo de migrantes foram divididas em migrantes de curta, média e longa duração de acordo com a duração da sua migração urbana. Neste estudo, foram evidenciados níveis bastantes el evados de actividade física nas raparigas migrantes, quando comparadas com estudos realizados nos Estado Unidos. As raparigas migrantes revelaram-se mais activas em relação às não-migrantes $(p<0.0001)$. Os valores do perímetro braquial, do índice de massa corporal e do índice de massa gorda eram, após ajustamento às diferenças em maturação sexual, significativamente el evados 
em função da duração da migração ( $p<0.01)$. No início da puberdade não havia diferenças nos valores de índice de massa corporal e de altura em função da idade. No entanto, a migração urbana resultou numa puberdade avançada e na mel horia do estado nutricional, mas sem catch-up no crescimento. Os resultados encontrados parecem suficientemente explicáveis pelas precárias condições de vida da zona rural, por um lado e, pela melhor aporte nutricional, não obstante uma elevada carga de trabal ho na zona urbana, por outro.

Micklesfield et al.(42) investigaram a relação entre a densidade mineral óssea e a actividade física em 144 mulheres sul-africanas com idade que variava dos 22 aos 59 anos. A densidade mineral óssea foi avaliada através do DEXA, e a actividade física monitorizada através de um questionário contemplando actividades domésticas, ocupacionais, de lazer e transporte. $O$ dispêndio energético total em MET/h foi estimado para quantificar a actividade física. A análise foi referenciada a quatro grupos etários, nomeadamente, 14-21; 22-34; 35-50 e mais de 50 anos. Embora a densidade mineral óssea não se tenha correlacionado significativamente com a actividade física total, entre as idades de 14 e 21 anos, as actividades de transporte incluindo caminhar e pedalar, a idade e o peso actual revelaram-se como os maiores determinantes da densidade óssea do fémur $\left(r^{2}=0.33, p<0.0001\right)$. Por outro lado, a densidade óssea da região lombar foi explicada pelo dispêndio energético nas actividades domésticas, idade e peso $\left(r^{2}=0.23, p<0.0001\right)$. Os coeficientes de correlação intraclasse calculados para medir o "tracking" da actividade física ao longo dos anos do estudo foram bastante elevados para o dispêndio energético total (0.98), actividades domésticas (0.98), actividades ocupacionais (0.78) e actividades de transporte (0.92). Os autores concluíram que o caminhar ou as actividades com impacto na idade jovem estão associadas a uma elevada densidade mineral óssea em idades mais avançadas. Por outro lado, os resultados desta pesquisa parecem sugerir uma estabilidade da actividade física ao longo do tempo.

A relação entre a densidade mineral óssea e a actividade física foi igualmente estudada em crianças sulafricanas, pelo contraste entre crianças negras e caucasianas de 9 anos de idade(41). A actividade física foi estimada de acordo com as componentes metabólica ( valores metabólicos derivados da intensidade, frequência e duração) e mecânica (somatório de todas as forças de reacção do solo multiplicado pela duração) e a densidade óssea através do DEXA. Foram encontradas diferenças étnicas nos padrões de actividade física, tendo as crianças caucasianas despendido valores significativamente mais elevados de energia em relação às crianças negras (21.7 \pm 2.9

MET.min ${ }^{-1}$ vs $9.5 \pm 0.5$ MET.min $\left.{ }^{-1} ; p<0.001\right)$. Ao dividir as crianças em quartís de acordo com o tempo e a intensidade de prática de actividades desportivas, as caucasianas mais activas apresentaram valores significativamente mais elevados de densidade mineral óssea de todo o corpo relativamente às crianças menos activas. De igual modo, as crianças brancas em quartís mais el evados de actividade física mecânica apresentaram valores mais el evados de densidade mineral óssea. Nesta população, a actividade física evidenciou uma associação osteogénica apenas nas crianças brancas, o que pode ser explicado pelos níveis baixos de actividade física encontrados neste grupo. Ainda assim, as raparigas negras apresentaram valores significativamente maiores de massa óssea na coluna e na bacia ( $p<0.001)$, mesmo depois de ajustá-los às dimensões corporais. De todo o modo, o estudo parece enaltecer o papel do exercício no incremento da massa óssea, o que assume funções importantes no mecanismo de protecção contra osteoporose em idades mais avançadas. Em Moçambique, Prista et al. (52) realizaram um estudo sobre uma amostra de 593 crianças e jovens de ambos os sexos dos 8 aos 15 anos e de diversos extractos sociais. A actividade física habitual foi avaliada através de um questionário concebido e validado para esta população específica(50, 56). Os resultados da aplicação do questionário revelaram que (1) as crianças e jovens de Maputo demonstravam hábitos de actividade relativamente intensas caracterizados por tarefas de sobrevivência não mecanizadas e jogos ao ar livre; (2) a actividade desportiva ocupava um espaço de pouca importância no dispêndio energético total (3) as raparigas e os mais desfavorecidos apresentavam níveis de actividade mais intensos que os rapazes e os sócio-economicamente privilegiados, respectivamente. 
O questionário criado em Moçambique tem vindo a ser aplicado em estudos relacionados com a evolução e significado da actividade física. Saranga et al.(não publicado) mostraram que os níveis de actividade física duma cidade Africana em transição estão a sofrer um acentuado declínio face às transformações sociais e económicas e física da cidade. Esta redução de actividade física pode explicar a observada redução do nível de aptidão física(59) e aumento da prevalência de factores de risco de doença cardiovascular(19) observada na mesma população e períodos em comparação. O questionário aplicado a uma amostra de 2316 rapazes e raparigas de Maputo com idades entre os 6 e 18 anos, foi utilizado para avaliar a relevância da classificação nutricional adoptada pela Organização Mundial de Saúde(58). Os autores demonstraram que os níveis de actividade não se diferenciavam entre os grupos nutricionais o que, associado a outros indicadores, colocaram em causa a relevância dos pontos de corte estabelecidos.

Em síntese, dos estudos dos padrões de actividade física realizados em África emerge o seguinte espectro de constatações: (i) a informação disponível sobre os estudos da aptidão física e actividade física realizados em África é bastante avulsa e dispersa; (ii) a abordagem pelo contraste entre o campo e a cidade parece ser a mais comum dos estudos consultados; (iii) a estimativa de dispêndio energético associado à actividade física das raparigas africanas é superior a das raparigas urbanas dos países desenvolvidos, porém bastante semelhante a de adolescentes de zonas rurais destes países; (iv) parece haver uma influência da migração urbana nos níveis de actividade física e que estes revelam uma diminuição ao longo da idade e (v) os níveis de actividade física habitual não se diferenciam entre grupos nutricionais, o que coloca em causa a relevância dos pontos de corte estabelecidos para as populações africanas.

\section{CONCLUSÕES}

Dos estudos revistos parece daro que a aptidão física das populações africanas, à excepção das variáveis em que o tamanho corporal é determinante, é superior em relação à que é observada nas populações europeias e americanas. No cômputo geral, as populações africanas expressam uma inferioridade estaturo-ponderal comparativamente às populações euro- peias e americanas. Face à predominância de actividades de sobrevivência que caracteriza a mai oria das populações africanas, a actividade física habitual destas testemunha uma ausência de estilo de vida sedentária, o que parece contribuir para que os seus níveis sejam superiores aos observados em países industrializados e na mai oria dos países em transição. Os valores de corte para a classificação do estado nutricional parecem desprovidos de qualquer relevância biológica para as populações africanas, já que tanto na aptidão física, quanto nos níveis de actividade física, os estudos revistos não testemunham nenhuma diferenciação entre grupos de estados nutricionais distintos, facto que parece denunciar uma falta de transcultural idade destes valores. 
REFERÊNCIAS BIBLIOGRÁFICAS

1. American Alliance for Health, Physical Education, Recreation and Dance (1980). H ealth Related Fitness Test Battery M anual. Reston, VA, AAPHERD.

2. Austin MD, Ghesquiere J, Azama M (1979). Work capacity and body morphology of Bantu and Pygmoid groups of western Zaire. Human Biology 51(1):79-89.

3. Badenhorst ML, Peters EM, Ash J (1992). Maximal work capacity and dietary status of rural black South African schoolboys aged 10-14 years. South A frican M edical Journal 81(16):504-508.

4. Bénéfice $E$ (1991). Nutritional status and development of working capacity of preschool Senegalese children. Early Child D evelopment and Care Vol. 72:47-59.

5. Bénéfice E (1992a). Growth and motor development of healthy Senegalese preschool children. A merican Journal of Human Biology 4:717-728.

6. Bénéfice $E$ (1992b). Physical activity and anthropometric and functional characteristics of mildly malnourished Senegalese children. A nn. Trop. Paediatr. 12(1):55-66.

7. Benéfice $E$, Malina R (1996). Body size, body composition and motor performance of mild-to-moderately undernourished Senegalese children. A nnals of H uman Biology 23(4):307-321.

8. Bénéfice E, Cames C (1999). Physical activity patterns of rural Senegalese adolescent girls during the dry and rainy seasons measured by movement registration and direct observation methods. Eur. J. Clin. Nutrition 53(8):636-43.

9. Bénéfice $E$, Fouére T, Malina R (1999). Early nutritional history and motor performance of Senegalese children, 4-6 years of age. A nnals of H uman Biology 26 (5):443-455.

10. Bénéfice $E$, Garnier D, N diaye G (2001a). High levels of habitual physical activity in West African adolescent girls and relationship to maturation, growth, and nutritional status: results from a 3-year prospective study. A m J H um Biol 13(6):808-20.

11. Bénéfice $E$, Garnier D, N diaye G (2001b). Assessment of physical activity among rural Senegalese adolescent girls: influence of age, sexual maturation, and body composition. Journal of A dolescent $\mathrm{H}$ ealth 28(4):319-27.

12. Bouchard C, Shephard RJ (1992). Physical activity, fitness and health: The model and key concepts. In: Bouchard, C; Shephard, RJ; Stevens, T (eds.). Physical activity, fitness and health. International Proceedings and Consensus Statement. Human Kinetics, 77-88.

13. Bouchard C, Shephard RJ, Stephens T, Sutton JR, Mcpherson BD (1988). Exercise, Fitness, and Health: The Consensus Statement. In: Bouchard et al (eds.). Exercise, Fitness, and $\mathrm{H}$ ealth: A Consensus of Current Knowledge. Human Kinetics Books, Champaign, Illinois, 3-31.

14. Cameron N (1991). Measurement issues related to the anthropometric assessment of nutritional status. In: J. Himes (ed.). A nthropometric assessment of nutritional status. Willey-Liss, pp.347-364.

15. Collins KJ, Abdel-Rahaman T, Awad El Karim MA (1988). Schistosomiasis: field studies of energy expenditure in agricultural workers in the Sudan. In: Collins, KJ; Roberts, DJ (eds.). Capacity of work in the tropics. Society for the Study of Human Biology Symposium 26, Cambridge: Cambridge University Press, pp. 235-247.

16. Corlet JT (1984). Power function analysis of physical performance by Tswana children. Journal of Sports Sciences 2:131-37.
17. Corlet JT (1986). Growth of urban school children in Botswana. A nnals of H uman Biology 13:73-82.

18. Corlet JT (1988). Strength Development of Tswana Children. Human Biology 60(4):569-577.

19. Damasceno A, Prista A (2002). Prevalência de factores de risco cardiovascular nas crianças da Cidade de Maputo. In Prista A, Maia J, Saranga S, Marques AT (eds). Saúde, crescimento e desenvolvimento: um estudo epidemiológico em crianças e jovens de M oçambique. FCDEF-Universidade do Porto, FCEFD-Universidade Pedagógica, Porto, Portugal, 89-96.

20. Davies C (1971a). Body composition in children: a refe rences standard for maximum aerobic power output on stationary bicycle ergometer. A cta Paediatr Scand Suppl. 1971; 217:136-7.

21. Davies C (1973b). Physiological response to exercise in East African children - 2. The effects of schistosomiasis, anaemia, and malnutrition. Env. Child $\mathrm{H}$ ealth 19:115-119.

22. Elnashir AM, Mayhew JL (1984). Physical fitness status of Egyptian children aged 9-18 years. British Journal of Sports M edicine 18 (1):26-29.

23. EUROFIT (1988). Handbook for the EUROFIT tests of physical fitness. Rome: Council of Europe Committee for the development of sport.

24. Eveleth P, Tanner J (1976). W orldwide variation in human growth (international biological program 8). Cambridge, Cambridge University Press.

25. Faye J, Seck K, Cisse F (1999). Transverse study compa ring certain physical characteristics of Senegalese children and adolescents from 7 to 13 years of age. Dakar M ed. 44(2):194-8.

26. Garnier D, Bénéfice $E$ (2001). Habitual physical activity of Senegalese adolescent girls under different working conditions, as assessed by a questionnaire and movement registration. A nnals of H uman Biology 28(1):79-97.

27. Garnier D, N diaye G, Bénéfice E (2003). Influence of urban migration on physical activity, nutritional status and growth of Senegalese adolescents of rural origin. Bull. Soc. Pathol. Exot. 96(3):223-7.

28. Goldstein H, Tanner J (1980). Ecological considerations on the use of anthropometry to assess nutritional status. Lancet 15; 1 (8168 Pt 1):582-5.

29. Goslin BR, Burden SB. (1986). Physical fitness of South African school children. Journal of Sports M edicine and Physical Fitness 26:128-136.

30. Guesquière J, Eeckles R (1981). Health, physical development and fitness of primary school children in Kinshasa. Children and Sport, 19-30.

31. Guesquière J, D'Hulst C, Nkiama E (1989). Fitness and oxygen uptake of children in the Ituri forest: natural selection or adaptation to the environment? International Journal of A nthropology 4:75-86.

32. Habitcht H, Matorel R, Yarbrough C, Malina R, Klein R (1974). Height and weight standards for preschool children. How relevant are ethnic differences in growth potential? Lancet 6;1(7858):611-614.

33. Henneberg M, Louw GJ (1998). Cross-sectional survey of growth of urban and rural "Cape Coloured" schoolchildren: anthropometry and functional tests. A merican Journal of Human Biology 10:73-85.

34. Henneberg M, Brush G, Harrison GA (2001). Growth of specific muscle strength between 6 and 18 years in contrasting socioeconomic conditions. A merican Journal of physical A nthropology 115:62-70. 
35. Hiernaux, J (1968). Ethnic differences in growth and deveIopment. Eugenics Quarterly 15(1):12-21.

36. Kvalsvig JD, Becker PJ (1988). Selective exposure of active and sociable children to schistosomiasis. A nnals of Tropical M edicine and Parasitology 82:417-414.

37. Latham MC, Stephenson LS, Kurz KM, Kinoti SN (1990). Metrifonate or Praziquantel treatment improves physical fitness and appetite of Kenyan schoolboys with Schistosoma haematobium and hookworms infections. A merican Journal of Tropical M edicine and H ygiene 43:170-179.

38. Maia JÁ, Prista A, Marques AT, Lopes V, Saranga S (2002). Estudo univariado e multivariados dos níveis de aptidão física. Efeitos da maturação biológica, do tamanho do corpo, do estatuto sócio-económico e da percentagem de gordura corporal. In Prista, A; Maia, JAR; Saranga, S; Marques, AT (eds.): Saúde, crescimento e desenvolvimento U m estudo epidemiológico em crianças e jovens de M oçambique. Fundação Calouste Gulbenkian, pp.49-69.

39. Malina R (1983). Socio-cultural influences of physical activity and performance. Bulletin de la Societé Belge d'A nthropologie et de Préhistorie. 94:155-76.

40. Martins D (1968). Dinâmica do crescimento e desenvolvimento da criança em M oçambique. Dissertação de Doutoramento apresentada à Faculdade de Medicina da Universidade de Coimbra, Portugal.

41. McVeigh JA, Norris SA, Cameron N, Pettifor JM (2004). Associations between physical activity and bone mass in black and white South African children at age 9 years. J A ppl Physiol. 97(3):1006-12.

42. Micklesfield L, Rosenberg L, Cooper D, Hoffman M, Kalla A, Stander I, Lambert E (2003). Bone mineral density and lifetime physical activity in South African women. Calcified Tissue International 73:463-469.

43. Muria A, Prista A, Maia JA (1999). Estudo da validade das medidas critério do Fitnessgram para a população escolar de Maputo. Revista da Sociedade Portuguesa de Educação Física 17/18: 111-116.

44. Ndamba, J (1986). Schistosomiasis: its effects on the physical performance of school children in Zimbabwe. Cent Afr J M ed. 32(12):289-93.

45. N damba J, Makaza N, Munjoma M, Gomo E, Kaondera KC (1993). The physical fitness and work performance of agricultural workers infected with Schistosoma mansoni in Zimbabwe. A nnals of Tropical M edicine and Parasitology 87 (6), pp. 553-561.

46. Nkiama E (1993). Physical fitness status of school children et Bunia in Zaire. In: A. Classens; J. Lefevre and Eynde (eds.). W orld Wide Variation in Physical Fitness. Katholieke Universiteit Leuven, 126-130.

47. Noakes TD, Benade AS, Jooste PL, Van Zyl F (1986). Analysis of the physical activity patterns of a rural Afrikaner population in the south-western Cape. South African M edical Journal 69:803-806.

48. OMS (1983). M esure des modifications de I'Etat nutritionnel. Organisation Mondiale de la Santé. Genéve.

49. Pieterse S, Manandhar M, Ismail S (2002). The association between nutritional status and handgrip strength in older Rwandan refugees. European Journal of Clinical Nutrition 56(10):933-9.

50. Prista A (1994). Influência da actividade física e dos factores sócio-económicos sobre as componentes da estrutura do valor físico relacionado com a saúde. Estudo em crianças e jovens
M oçambicanos. Dissertação apresentada às provas de Doutoramento. FCDEF-UP. Porto.

51. Prista A (1995). Crescimento, actividade física e aptidão física em países não industrializados: abordagem biocultural em crianças e jovens de Moçambique. R evista A gon 2:85-102.

52. Prista A, Marques AT, Maia JA (1997). Relationship between physical activity, socioeconomic status and physical fitness of 8-15 year old youth from Mozambique. A merican Journal of Human Biology 9: 449-57.

53. Prista A (1998). Nutritional status, physical fitness and physical activity in children and youth in Maputo, Mozambique. In: J. Parizková and A.P.Hills (eds.) - Physical fitness and nutrition during growth. M edicine and Sport Science Reviews. Basel: Karger, 94-104.

54. Prista A, Maia JA, Marques AT (1998). Sexual dimorphism in physical fitness. A multivariate study. M edicine and Science in Sports and Exercise 5:S155.

55. Prista A, Marques AT, Maia JA (1999). Allometric scaling of physical performance in children and youth forma Maputo, Mozambique. M edicine and Science in Sports and Exercise 5:S92.

56. Prista A, Marques AT, Maia JA (2000). Empirical validation of na instrument to measure habitual physical activity in youth from Maputo, Mozambique. A merican Journal of H uman Biology 12(4):437-446.

57. Prista A, Maia JA, Beunen G, Damasceno A (2002). Saúde, crescimento e desenvolvimento. U m estudo epidemiológico em crianças e jovens de M oçambique. Fundação Calouste Gulbenkian. Lisboa.

58. Prista A, Maia JA, Damasceno A, Beunen G (2003). Anthropometric indicators of nutritional status: implications for fitness, activity, and health in school-age children and adolescents from Maputo, Mozambique. A merican Journal of Clinical Nutrition 77(4):952-9.

59. Saranga S, Prista A, Maia JA (2002). Mudanças nos níveis de aptidão física em função de alterações políticas e sócioeconómicas de 1992-1999. In: Prista, A; Maia, JAR; Saranga, S; Marques, AT (eds.). Saúde, crescimento e desenvolvimento - U m estudo epidemiológico em crianças e jovens de M oçambique. Fundação Calouste Gulbenkian, pp.71-87.

60. Sparling PB, Noakes TD, Steyn K, Jordaan E, Jooste PL, Bourne LT, Badenhorst C (1994). Level of physical activity and CHD risk factors in black South African men. M ed. Sci. Sports Exerc. 26(7):896-902.

61. Spurr GB (1988). Body size, physical work capacity and productivity in hard work: Is bigger better? In Waterlow (ed.): Linear growth retardation in less developed countries. New York-Raven Press, 14:215-224.

62. Stephenson LS, Latham MC, Kurz KM, Miller D, Kinoti SN, Oduori ML (1985). Urinary iron loss and physical fitness of Kenyan children with urinary schistosomiasis. A merican Journal of Tropical M edicine and Hygiene 34 (2), pp. 322-330.

63. Stephenson LS, Latham MC, Kinoti SN, Kurz KM, Brigham H (1990). Improvements in physical fitness of Kenyan schoolboys infected with hookworm, Trichuris trichiura and Ascaris lumbricoides following a single dose of albendazole. Transactions of the Royal Society of Tropical Medicine and Hygiene 84: 277-282.

64. Stephenson LS, Latham MC, Adams EJ, Kinoti SN, Pertet A (1993). Physical fitness, growth and appetite of Kenyan 
school boys with Hookworm, Trichuris trichiura and Ascaris lumbricoides infections are improved four months after a single dose of albendazole. Journal of Nutrition 123(6): 1036-1046.

65. Toriola A, Igbokwe N (1986). Age and sex differences in motor performances of preschool Nigerian children. Journal of Sports Sciences 4:219-227.

66. Walker AP, Faith WB, Barbara DR, Smit PJ (1972). Running performance in South African Bantu children with schistosomiasis. Tropical and Geographical M edicine 24(1972):347-352.

67. World Health Organization (1983). M easuring chance in nutritional status: Guidelines for assessing the nutritional status impact of supplementary feeding programs for vulnerable groups. Geneve: World Health Organization.

68. World Health Organization Working Group (1986). Use and interpretation of anthropometric indicators of nutritional status. Bulletin of World Health O rganization 64:929-941.

69. World Health Organization (1995). Physical status: the use and interpretation of anthropometry. R eport of a W HO Expert Committee. WHO Technical Report Series, 854, Geneve: World Health Organization.

70. Wyndham CH (1973). The Work capacity of rural and urban Bantu in South Africa. South African M edical Journal 47(28):1239-1244.

\section{APÊNDICE \\ Os Quadros-A1:A5 resumem o essencial da informa- ção tratada nas diferentes secções de que o artigo é composto.}




\begin{tabular}{|c|c|c|c|c|c|}
\hline Autor[es] & Amostra & Objectivos & Variáveis & Resultados & País \\
\hline $\begin{array}{l}\text { Elnashare } \\
\text { Mayhew } \\
{[1984]}\end{array}$ & $\begin{array}{l}710 \text { sujeitos } \\
\text { dos } 9 \text { e aos } \\
18 \text { anos de } \\
\text { ambos os } \\
\text { sexos. }\end{array}$ & $\begin{array}{l}\text { Comparação dos } \\
\text { niveis de aptidão } \\
\text { física de crianças } \\
\text { egípcias com as } \\
\text { normas de AAHPER. }\end{array}$ & $\begin{array}{l}\text { Bateria } \\
\text { AAHPER } \\
(1980)\end{array}$ & $\begin{array}{l}\text { As crianças egípcias apresentaram } \\
\text { resultados mais baixos na maioria } \\
\text { dos testes em relação às normas } \\
\text { americanas. }\end{array}$ & $\begin{array}{l}\text { Egipto } \\
\text { [Fayoum] }\end{array}$ \\
\hline $\begin{array}{l}\text { Ghesquiere } \\
\text { et al. } \\
\text { (1989) }\end{array}$ & & $\begin{array}{l}\text { Comparação dos } \\
\text { valores obtidos nos } \\
\text { testes do Eurofit por } \\
\text { crianças e jovens da } \\
\text { floresta Ituri com } \\
\text { valores de crianças e } \\
\text { jovens europeus. }\end{array}$ & $\begin{array}{l}\text { Bateria } \\
\text { Eurofit }\end{array}$ & $\begin{array}{l}\text { Os sujeitos europeus obtiveram } \\
\text { melhores somente nos testes em } \\
\text { que a sua maior estatura lhes } \\
\text { conferia vantagem }\end{array}$ & $\begin{array}{l}\text { Zaire } \\
\text { [Floresta } \\
\text { Ituri] }\end{array}$ \\
\hline $\begin{array}{l}\text { Nkiama } \\
\text { (1993) }\end{array}$ & $\begin{array}{l}\text { População } \\
\text { escolar de } \\
\text { ambos os } \\
\text { sexos dos } 6 \\
\text { aos } 20 \text { anos. }\end{array}$ & $\begin{array}{l}\text { Comparação dos } \\
\text { níveis de aptidão } \\
\text { física crianças e } \\
\text { jovens do Zaire com } \\
\text { valores de crianças e } \\
\text { jovens Belgas. }\end{array}$ & $\begin{array}{l}\text { Bateria } \\
\text { Eurofit }\end{array}$ & $\begin{array}{l}\text { Foi evidente a superioridade dos } \\
\text { belgas nos testes em que a } \\
\text { influência da maturação e/ou da } \\
\text { altura é determinante. }\end{array}$ & $\begin{array}{l}\text { Zaire } \\
\text { (Bunia) }\end{array}$ \\
\hline $\begin{array}{l}\text { Prista } \\
\text { (1994] }\end{array}$ & $\begin{array}{l}593 \text { sujeitos } \\
\text { de ambos os } \\
\text { sexos dos } 8 \\
\text { aos } 15 \text { anos. }\end{array}$ & $\begin{array}{l}\text { Comparação dos } \\
\text { niveis de aptidão } \\
\text { física de crianças e } \\
\text { jovens } \\
\text { moçambicanos com } \\
\text { as normas } \\
\text { americanas e } \\
\text { europeias. }\end{array}$ & $\begin{array}{l}\text { Baterias } \\
\text { AHPERD } \\
\text { (1980) e } \\
\text { EUROFIT } \\
\text { (1988) }\end{array}$ & $\begin{array}{l}\text { Os moçambicanos revelaram } \\
\text { performances superiores em relação } \\
\text { às normas da AAHPERD e estudos } \\
\text { com Europeus não apenas em } \\
\text { tarefas onde a massa muscular } \\
\text { absoluta é determinante, como } \\
\text { também em termos de resistência } \\
\text { cardiorespiratória, agilidade e } \\
\text { flexibilidade }\end{array}$ & $\begin{array}{l}\text { Moçambique } \\
\text { (Maputo) }\end{array}$ \\
\hline $\begin{array}{l}\text { Muria et al., } \\
\text { (1999) }\end{array}$ & $\begin{array}{l}547 \text { crianças } \\
\text { e jovens dos } \\
8 \text { aos } 11 \\
\text { anos de } \\
\text { ambos os } \\
\text { sexos. }\end{array}$ & $\begin{array}{l}\text { Testagem, em } \\
\text { populaçōes } \\
\text { Africanas, dos } \\
\text { critérios sugeridos } \\
\text { pela bateria da } \\
\text { Prudential } \\
\text { Fitnessgram. }\end{array}$ & $\begin{array}{l}\text { Bateria } \\
\text { Fitnessgram }\end{array}$ & $\begin{array}{l}\text { Foram encontrados valores } \\
\text { percentuais superiores a } 50 \% \text { de } \\
\text { crianças de ambos os sexos com } \\
\text { valores iguais e/ou superiores aos } \\
\text { critérios adoptadas pelo } \\
\text { Fitnessgram. }\end{array}$ & $\begin{array}{l}\text { Moçambique } \\
\text { (Maputo) }\end{array}$ \\
\hline $\begin{array}{l}\text { Faye et al. } \\
\text { (1999) }\end{array}$ & $\begin{array}{l}\text { P00 sujeitos } \\
\text { dos } ? \text { aos } 13 \\
\text { anos de } \\
\text { ambos os } \\
\text { sexos. }\end{array}$ & $\begin{array}{l}\text { Estudo da dinâmica } \\
\text { da expressão de } \\
\text { algumas } \\
\text { capacidades físicas } \\
\text { em função da idade e } \\
\text { género. }\end{array}$ & $\begin{array}{l}\text { Velocidade, } \\
\text { velocidade } \\
\text { de } \\
\text { coordenação, } \\
\text { potência, } \\
\text { flexibilidade } \\
\text { e equilibrio } \\
\end{array}$ & $\begin{array}{l}\text { Os rapazes obtiveram melhores } \\
\text { resultados que as raparigas nos } \\
\text { testes de velocidade e potência e } \\
\text { estas nos testes de flexibilidade e } \\
\text { de equilibrio. }\end{array}$ & Senegal \\
\hline $\begin{array}{l}\text { Maia et al. } \\
{[2002]}\end{array}$ & $\begin{array}{l}\text { Avaliação do } \\
\text { efeito da } \\
\text { maturação } \\
\text { biológica, do } \\
\text { tamanho do } \\
\text { corpo, do } \\
\text { estatuto } \\
\text { sócio- } \\
\text { económico e } \\
\text { da } \\
\text { percentagem } \\
\text { de gordura } \\
\text { na aptidão } \\
\text { fisica. }\end{array}$ & $\begin{array}{l}2503 \text { crianças e } \\
\text { jovens dos } 8 \text { aos } 17 \\
\text { anos de ambos os } \\
\text { sexos }\end{array}$ & $\begin{array}{l}\text { Nove (9) } \\
\text { provas } \\
\text { provenientes } \\
\text { das baterias } \\
\text { do Eurofit, } \\
\text { Fitnessgram } \\
\text { e AAHPERD. }\end{array}$ & $\begin{array}{l}\text { Foi confirmado o efeito } \\
\text { determinante da idade e do género } \\
\text { mesmo depois de controlado o } \\
\text { efeito da massa corporal, estágio } \\
\text { maturacional e estatuto sócio- } \\
\text { económico. }\end{array}$ & $\begin{array}{l}\text { Moçambique } \\
\text { (Maputo] }\end{array}$ \\
\hline
\end{tabular}

Quadro A1. Sinopse dos estudos descritivos sobre a aptidão física em Árica. 


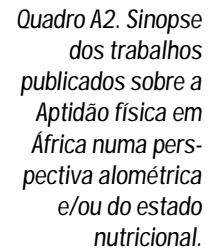

\begin{tabular}{|c|c|c|c|c|c|}
\hline Autor[es] & Amostra & Objectivos & Variáveis & Resultados & País \\
\hline $\begin{array}{l}\text { Corlett } \\
\text { (1984) }\end{array}$ & $\begin{array}{l}240 \text { crianças, } \\
\text { dos } ? \text { aos } 12 \\
\text { anos de ambos } \\
\text { os sexos. }\end{array}$ & $\begin{array}{l}\text { Estudo dos } \\
\text { efeitos das } \\
\text { variáveis } \\
\text { dimensionais na } \\
\text { aptidão física. }\end{array}$ & $\begin{array}{l}\text { Variáveis } \\
\text { somáticas, } \\
\text { provas de força } \\
\text { estática, } \\
\text { impulsão vertical } \\
\text { e longitudinale } \\
\text { corrida. }\end{array}$ & $\begin{array}{l}\text { Foi revelada a ausência do } \\
\text { pressuposto de similaridade } \\
\text { geométrica nas diferenças } \\
\text { encontradas entre os expoentes } \\
\text { dimensionais teóricose } \\
\text { empíricos. }\end{array}$ & Botswana \\
\hline $\begin{array}{l}\text { Bénéfice } \\
\text { (1991, } \\
1992)\end{array}$ & $\begin{array}{l}88 \text { crianças } \\
\text { rurais saudáveis } \\
\text { dos } 3 \text { aos } 6 \\
\text { anos de ambos } \\
\text { os sexos. }\end{array}$ & $\begin{array}{l}\text { Estudo do } \\
\text { crescimento } \\
\text { somático e o } \\
\text { desenvolvimento } \\
\text { da capacidade } \\
\text { de trabalho e } \\
\text { avaliação do } \\
\text { impacto do seu } \\
\text { estatuto } \\
\text { nutricional na } \\
\text { resposta } \\
\text { cardiovascular } \\
\text { ao exercício. }\end{array}$ & $\begin{array}{l}\text { Medidas } \\
\text { antropométricas, } \\
\text { provas de } 20 \\
\text { metros de } \\
\text { corrida, salto em } \\
\text { comprimento, } \\
\text { força de preensão } \\
\text { e arremesso de } \\
\text { bola e o teste de } \\
\text { degrau adaptado } \\
\text { de Cermák et al. } \\
\text { (1969). }\end{array}$ & $\begin{array}{l}\text { Rácios peso e altura para idade } \\
\text { das crianças senegalesas abaixo } \\
\text { da mediana dos valores de NCHS. } \\
\text { WHO (1983). Na aptidão } \\
\text { cardiorespiratória não houve } \\
\text { diferenças significativas entre as } \\
\text { diferentes coortes, senão apenas } \\
\text { em função do género e a favor dos } \\
\text { rapazes. Estes valores, quando } \\
\text { contrastados com os de crianças } \\
\text { Checas revelam desvantagens } \\
\text { somáticas e de aptidão fisica das } \\
\text { crianças senegalesas. }\end{array}$ & $\begin{array}{l}\text { Senegal } \\
\text { (Bambey) }\end{array}$ \\
\hline $\begin{array}{l}\text { Toriola e } \\
\text { Igbokwe } \\
\text { [1996] }\end{array}$ & $\begin{array}{l}341 \text { crianças } \\
\text { dos } 3 \text { aos } 5 \\
\text { anos de ambos } \\
\text { os sexos. }\end{array}$ & $\begin{array}{l}\text { Comparação da } \\
\text { performance } \\
\text { motora em } \\
\text { função do género } \\
\text { e da idade } \\
\text { cronológica. }\end{array}$ & $\begin{array}{l}\text { Bateria de testes } \\
\text { desenvolvida por } \\
\text { Morris et al. } \\
\text { (1981). }\end{array}$ & $\begin{array}{l}\text { Melhores prestações dos rapazes } \\
\text { em relação às raparigas na } \\
\text { maioria dos testes motores e um } \\
\text { incremento dos níveis de } \\
\text { performance dos grupos ao longo } \\
\text { da idade. }\end{array}$ & Nigéria \\
\hline $\begin{array}{l}\text { Benéfice e } \\
\text { Malina } \\
{[1996]}\end{array}$ & $\begin{array}{l}348 \text { crianças } \\
\text { moderadamente } \\
\text { subnutridas dos } \\
5 \text { aos } 13 \text { anos } \\
\text { de ambos os } \\
\text { sexos. }\end{array}$ & $\begin{array}{l}\text { Estudo da } \\
\text { relação entre as } \\
\text { características } \\
\text { antropométricas } \\
\text { e a performance } \\
\text { motora e a } \\
\text { influência das } \\
\text { dimensõese } \\
\text { composição } \\
\text { corporais na } \\
\text { variabilidade da } \\
\text { performance } \\
\text { motora. }\end{array}$ & $\begin{array}{l}\text { Medidas } \\
\text { antropométricas, } \\
\text { provas de } \\
\text { velocidade, } \\
\text { arremesso de } \\
\text { bola, impulsão } \\
\text { horizontal sem } \\
\text { corrida } \\
\text { preparatória e } \\
\text { força de preensão } \\
\text { manual. }\end{array}$ & $\begin{array}{l}\text { A altura e o peso explicavam } 30 \text { - } \\
50 \% \text { da variância na performance } \\
\text { das crianças com menos de } 10 \\
\text { anos, enquanto que nas crianças } \\
\text { com mais de } 10 \text { anos, o peso } \\
\text { explicava cerca de } 10-25 \% \text { da } \\
\text { variância. }\end{array}$ & $\begin{array}{l}\text { Senegal } \\
\text { (Lambaye) }\end{array}$ \\
\hline $\begin{array}{l}\text { Prista } \\
\text { (1998) }\end{array}$ & $\begin{array}{l}316 \text { crianças e } \\
\text { jovens dos } 11 \\
\text { aos } 14 \text { anos de } \\
\text { ambos os sexos }\end{array}$ & $\begin{array}{l}\text { Avaliação da } \\
\text { aptidão física e } \\
\text { identificação da } \\
\text { relevância das } \\
\text { medidas } \\
\text { antropométricas } \\
\text { como } \\
\text { indicadores do } \\
\text { estatuto } \\
\text { nutricional } \\
\text { (WH0,1983). }\end{array}$ & $\begin{array}{l}\text { Medidas } \\
\text { antropométricas, } \\
\text { actividade física e } \\
\text { testes motores } \\
\text { seleccionados das } \\
\text { baterias AAHPERD } \\
{[1980] \text { e Eurofit }} \\
\text { [1988]. }\end{array}$ & $\begin{array}{l}\text { Ainda que de acordo com os } \\
\text { critérios da WHO (1983) } 46.2 \% \text { da } \\
\text { amostra tenha demonstrado } \\
\text { algum sinal de malnutriçāo, a } \\
\text { aptidão física só se diferenciou } \\
\text { nas tarefas em que a massa } \\
\text { muscular era determinante. Na } \\
\text { actividade fisica, nenhum efeito } \\
\text { do estatuto nutricional pôde ser } \\
\text { observado. }\end{array}$ & $\begin{array}{l}\text { Moçambique } \\
\text { [Maputo] }\end{array}$ \\
\hline
\end{tabular}




\begin{tabular}{|c|c|c|c|c|c|}
\hline $\begin{array}{l}\text { (Bénéfice } \\
\text { et al., } \\
1999 \text { ) }\end{array}$ & $\begin{array}{l}139 \text { crianças } \\
\text { dos } 3 \text { aos } 6 \\
\text { anos de ambos } \\
\text { os sexos. }\end{array}$ & $\begin{array}{l}\text { Comparação da } \\
\text { coordenação e a } \\
\text { performance } \\
\text { motoras em } \\
\text { função do estado } \\
\text { nutricional. }\end{array}$ & $\begin{array}{l}\text { Medidas } \\
\text { antropométricas, } \\
6 \text { testes de } \\
\text { coordenação } \\
\text { motora e } 5 \text { testes } \\
\text { motores. }\end{array}$ & $\begin{array}{l}\text { Crianças bem nutridas obtiveram } \\
\text { melhores prestações na maioria } \\
\text { dos testes do que as com } \\
\text { subnutrição crónica e severa. As } \\
\text { dimensões corporais explicaram } \\
\text { uma significativa parte da } \\
\text { variância da aptidão motora, } \\
\text { tendo sido a altura a revelar-se } \\
\text { como melhor predictor. }\end{array}$ & $\begin{array}{l}\text { Senegal } \\
\text { (Lambaye) }\end{array}$ \\
\hline $\begin{array}{l}\text { Pieterse et } \\
\text { al. [2002] }\end{array}$ & $\begin{array}{l}828 \text { sujeitos } \\
\text { adultos dos } 50 \\
\text { aos } 92 \text { anos de } \\
\text { amos os sexos. }\end{array}$ & $\begin{array}{l}\text { Estudo da } \\
\text { associação entre } \\
\text { o estatuto } \\
\text { nutricional e a } \\
\text { força de } \\
\text { preensão } \\
\text { manual. }\end{array}$ & $\begin{array}{l}\text { Variáveis } \\
\text { antropométricas } \\
\text { e teste de } \\
\text { dinamometria } \\
\text { manual. }\end{array}$ & $\begin{array}{l}\text { A força de preensão } \\
\text { correlacionou-se positivamente } \\
\text { com o índice de massa corporal } \\
{[\text { [ ,r=0.26; ,r=0.16) e com o }} \\
\text { perimetro braquial ( , r=0.41; , } \\
r=0.26 \text { ], } 0 \text { indice de massa } \\
\text { corporal revelou-se uma variável } \\
\text { contribuinte para a variação da } \\
\text { força de preensão, mesmo depois } \\
\text { de controlar o efeito do género, } \\
\text { idade e altura. }\end{array}$ & Ruanda \\
\hline $\begin{array}{l}\text { Prista et } \\
\text { al. (2003) }\end{array}$ & $\begin{array}{l}2316 \text { crianças e } \\
\text { jovens dos } 6 \text { aos } \\
18 \text { anos de } \\
\text { ambos os sexos. }\end{array}$ & $\begin{array}{l}\text { Avaliação da } \\
\text { aptidão fisica e } \\
\text { identificação da } \\
\text { relevância das } \\
\text { medidas } \\
\text { antropométricas } \\
\text { como } \\
\text { indicadores do } \\
\text { estatuto } \\
\text { nutricional } \\
\text { (WH0,1995). }\end{array}$ & $\begin{array}{l}\text { Indicadores } \\
\text { antropométricos, } \\
\text { estatuto } \\
\text { maturacional, } \\
\text { variáveis clínicas, } \\
\text { actividade física e } \\
\text { testes de aptidão } \\
\text { física } \\
\text { seleccionados das } \\
\text { baterias AAHPERD } \\
\text { (1980) e Eurofit } \\
\text { (1988). }\end{array}$ & $\begin{array}{l}\text { Não foi encontrada relevância nos } \\
\text { critérios que classificam } \\
\text { subnutrição, se bem que tenha } \\
\text { sido revelada validade nos valores } \\
\text { de corte para definição de } \\
\text { sobrepeso e obesidade. }\end{array}$ & $\begin{array}{l}\text { Moçambique } \\
\text { (Maputo) }\end{array}$ \\
\hline
\end{tabular}


Quadro A3. Sinopse dos estudos sobre Aptidão física e estatuto sócio-económico em África.

\begin{tabular}{|c|c|c|c|c|c|}
\hline Autor(es] & Amostra & Objectivos & Variáveis & Resultados & País \\
\hline $\begin{array}{l}\text { Davies et } \\
\text { al. (1973) }\end{array}$ & $\begin{array}{l}94 \text { jovens } \\
\text { adultos dos } \\
18 \text { aos } 30 \\
\text { anos de } \\
\text { ambos os } \\
\text { sexos. }\end{array}$ & $\begin{array}{l}\text { Avaliação e } \\
\text { comparação da } \\
\text { aptidão aeróbia } \\
\text { e composição } \\
\text { corporal. }\end{array}$ & $\begin{array}{l}\text { Composição } \\
\text { corporal e aptidão } \\
\text { aeróbia medida } \\
\text { através de um } \\
\text { teste de esforço } \\
\text { submaximal e } \\
\text { maximal em } \\
\text { cicloergómetro. } \\
\end{array}$ & $\begin{array}{l}\text { Os africanos evidenciaram valores } \\
\text { inferiores de peso, altura, massa } \\
\text { isenta de gordura e volume da } \\
\text { perna em relação aos europeus, } \\
\text { os quais apresentaram ainda e } \\
\text { em ambos os sexos, valores } \\
\text { absolutos de } \mathrm{VO}_{2} \text { máx superiores } \\
\text { aos africanos. }\end{array}$ & $\begin{array}{l}\text { Tanzânia } \\
\text { [Dar-es-Salamm] }\end{array}$ \\
\hline $\begin{array}{l}\text { Wyndham } \\
\text { (1973] }\end{array}$ & $\begin{array}{l}906 \text { sujeitos } \\
\text { Bantus de } \\
\text { ambos os } \\
\text { sexos, com } \\
\text { valores } \\
\text { médios de } \\
\text { idade de } 32 \text {. } \\
40 \text { anos. }\end{array}$ & $\begin{array}{l}\text { Avaliação da } \\
\text { influência do } \\
\text { peso corporal, } \\
\text { idade, género e } \\
\text { da altitude } \\
\text { sobre a } \\
\text { capacidade de } \\
\text { trabalho em } \\
\text { funçãoà } \\
\text { localização } \\
\text { geográfica. }\end{array}$ & $\begin{array}{l}\text { Peso, altura, } \\
\text { composição } \\
\text { corporal e } \mathrm{O}_{2} \text { máx. }\end{array}$ & $\begin{array}{l}\text { Os sujeitos Bantus da zona rural } \\
\text { apresentaram valores mais } \\
\text { baixos de peso e de } \mathrm{VO}_{2} \text { máx em } \\
\text { relação aos da zona urbana. } 0 \mathrm{~s} \\
\text { valores de } \mathrm{VO}_{2} \text { máx de sujeitos sul- } \\
\text { africanos } \mathrm{Bantus} \text { da zona urbana } \\
\text { eram similares aos encontrados } \\
\text { em trabalhadores noruegueses da } \\
\text { indústria e em mineiros brancos } \\
\text { do intervalo etário de } 30.39 \text { anos. }\end{array}$ & $\begin{array}{l}\text { África do Sul } \\
\text { [Venda e Pedi] }\end{array}$ \\
\hline $\begin{array}{l}\text { Austin et al. } \\
\text { (1979] }\end{array}$ & $\begin{array}{l}169 \text { homens } \\
\text { e mulheres } \\
\text { dos } 18 \text { aos } \\
40 \text { anos } \\
\text { pertencentes } \\
\text { às etnias } \\
\text { Ntomba e } \\
\text { Twa. }\end{array}$ & $\begin{array}{l}\text { Comparação da } \\
\text { capacidade de } \\
\text { trabalho e a } \\
\text { morfologia entre } \\
\text { dois grupos } \\
\text { étnicos. }\end{array}$ & $\begin{array}{l}\text { Indicadores } \\
\text { somáticos e } \\
\text { potência máxima } \\
\text { aeróbia. }\end{array}$ & $\begin{array}{l}\text { A etnia Ntomba apresentou } \\
\text { médias mais elevadas no peso e } \\
\text { altura, enquanto que a } \\
\text { composição corporal se revelou } \\
\text { idêntica. Em termos de } \mathrm{VO}_{2} \text { máx, a } \\
\text { etnia Ntomba obteve valores } \\
\text { médios absolutos mais elevados, } \\
\text { que quando relativizados ao peso } \\
\text { corporal o deixavam de ser. }\end{array}$ & Zaire \\
\hline $\begin{array}{l}\text { Gosline } \\
\text { Burden } \\
{[1986]}\end{array}$ & $\begin{array}{l}222 \text { sujeitos } \\
\text { do ensino } \\
\text { secundário } \\
\text { de ambos os } \\
\text { sexos. }\end{array}$ & $\begin{array}{l}\text { Avaliação e } \\
\text { comparação da } \\
\text { aptidão fisica } \\
\text { em função do } \\
\text { grupo étnico. }\end{array}$ & $\begin{array}{l}\text { Peso, altura, } \\
\text { composição } \\
\text { corporal e testes } \\
\text { motores de } \\
\text { flexibilidade, } \\
\text { agilidade, força, } \\
\text { equilibrio, } \\
\text { potência } \\
\text { anaeróbia e } \\
\text { aeróbia, } \\
\text { resistência } \\
\text { muscular e } \\
\text { cardiorespiratória. }\end{array}$ & $\begin{array}{l}\text { As crianças brancas } \\
\text { apresentaram melhores valores } \\
\text { somáticos em relação aos demais } \\
\text { grupos; as crianças negras } \\
\text { obtiveram melhores resultados ao } \\
\text { nivel da força. } 0 \mathrm{VO}_{2} \text { máx estimado } \\
\text { revelou um maior potencial } \\
\text { aeróbio das crianças brancas em } \\
\text { relação às mestiças e negras e } \\
\text { destas em relação às mestiças. }\end{array}$ & África do Sul \\
\hline $\begin{array}{l}\text { Corlett } \\
\text { [1988] }\end{array}$ & $\begin{array}{l}612 \text { crianças } \\
\text { dos } ? \text { aos } 12 \\
\text { anos de } \\
\text { ambos os } \\
\text { sexos. }\end{array}$ & $\begin{array}{l}\text { Avaliação e } \\
\text { comparação da } \\
\text { força em } \\
\text { crianças de } \\
\text { meios sócio- } \\
\text { económicos } \\
\text { contrastantes, } \\
\text { i.e., meios rural } \\
\text { e urbano. }\end{array}$ & $\begin{array}{l}\text { Peso, altura, } \\
\text { perímetro braquial } \\
\text { e força de } \\
\text { preensão manual. }\end{array}$ & $\begin{array}{l}\text { Foi notório um efeito significativo } \\
\text { da idade, do género sexual e da } \\
\text { área geográfica, e observou-se } \\
\text { que os niveis de força } \\
\text { aumentavam ao longo da idade. } \\
\text { Os rapazes apresentaram } \\
\text { melhores resultados que as } \\
\text { raparigas em todas as idades e as } \\
\text { crianças urbanas superaram as } \\
\text { do meio rural em ambos os sexos, } \\
\text { mesmo após o ajustamento } \\
\text { dimensional para diferenças de } \\
\text { tamanho. }\end{array}$ & Botswana \\
\hline
\end{tabular}




\begin{tabular}{|c|c|c|c|c|c|}
\hline $\begin{array}{l}\text { Badenhorst } \\
\text { et al. } \\
\text { (1992] }\end{array}$ & $\begin{array}{l}94 \text { jovens } \\
\text { adultos de } \\
\text { ambos os } \\
\text { sexos }\end{array}$ & $\begin{array}{l}\text { Comparação dos } \\
\text { níveis de } \\
\text { aptidão física } \\
\text { em função do } \\
\text { estatuto sócio- } \\
\text { económico e } \\
\text { estado } \\
\text { nutricional. }\end{array}$ & $\begin{array}{l}\text { Peso, altura, } \\
\text { pregas de } \\
\text { adiposidade, } \\
\mathrm{VO}_{2} \text { máx, } \\
\text { actividade física } \\
\text { habitual e } \\
\text { estatuto } \\
\text { nutricional. }\end{array}$ & $\begin{array}{l}\text { Os resultados revelaram uma } \\
\text { ingestão calórica na ordem dos } \\
37-41 \% \text { Kj inferior em relação à } \\
\text { quantidade diária recomendada; } \\
\text { uma ingestão satisfatória de } \\
\text { proteínas; baixa percentagem de } \\
\text { gordura corporal; ausência de } \\
\text { situações de "stunting" ou } \\
\text { "wasting" e valores de } \mathrm{VO}_{2} \text { máx } \\
\text { comparáveis aos encontrados por } \\
\text { outros autores para crianças da } \\
\text { mesma idade. }\end{array}$ & África do Sul \\
\hline $\begin{array}{l}\text { Prista et } \\
\text { al. (1997) }\end{array}$ & $\begin{array}{l}593 \text { crianças } \\
\text { e jovens dos } \\
8 \text { aos } 15 \\
\text { anos de } \\
\text { ambos os } \\
\text { sexos. }\end{array}$ & $\begin{array}{l}\text { Estudo da } \\
\text { influência do } \\
\text { estatuto sócio- } \\
\text { económico } \\
\text { [ESE] nos } \\
\text { valores da } \\
\text { aptidão física. }\end{array}$ & $\begin{array}{l}\text { Peso, Altura, pregas } \\
\text { adiposas, } \\
\text { composição } \\
\text { corporal, estatuto } \\
\text { sócio-económico } \\
\text { e testes motores } \\
\text { de agilidade, } \\
\text { flexibilidade, força } \\
\text { de preensão } \\
\text { manual, força de } \\
\text { resistência } \\
\text { abdominal e } \\
\text { resistência } \\
\text { cardiorespiratória. }\end{array}$ & $\begin{array}{l}\text { Os individuos de ESE mais baixo } \\
\text { revelaram niveis mais elevados } \\
\text { de aptidão física nas provas de } \\
\text { força de resistência abdominal, } \\
\text { agilidade e resistência } \\
\text { cardiorespiratória, enquanto que } \\
\text { no teste de flexibilidade os seus } \\
\text { niveis foram baixos. No entanto, } \\
\text { na prova de força de preensão } \\
\text { manual não se notou qualquer } \\
\text { influência do ESE. }\end{array}$ & $\begin{array}{l}\text { Moçambique } \\
\text { (Maputo) }\end{array}$ \\
\hline $\begin{array}{l}\text { Henneberg } \\
\text { \& Louw } \\
{[1998]}\end{array}$ & $\begin{array}{l}3748 \\
\text { criançase } \\
\text { jovens dos } 5 \\
\text { aos } 19 \text { anos } \\
\text { dos dois } \\
\text { sexos. }\end{array}$ & $\begin{array}{l}\text { Estudo de } \\
\text { padrões de } \\
\text { crescimento } \\
\text { somático e } \\
\text { avaliação da } \\
\text { aptidão física } \\
\text { em crianças do } \\
\text { meio urbano e } \\
\text { rural. }\end{array}$ & $\begin{array}{l}\text { Indicadores } \\
\text { somáticos, força } \\
\text { de preensão } \\
\text { manual, } \\
\text { velocidade de } \\
\text { reacçãoe } \\
\text { frequência } \\
\text { cardiaca. }\end{array}$ & $\begin{array}{l}\text { Os sujeitos de ESE mais baixo } \\
\text { apresentaram valores da força de } \\
\text { preensão manual e do tempo de } \\
\text { reacção inferiores em relação ao } \\
\text { outro grupo de ESE mais alto. }\end{array}$ & $\begin{array}{l}\text { África do Sul } \\
\text { [Cabo e Klein } \\
\text { Karoo] }\end{array}$ \\
\hline $\begin{array}{l}\text { Henneberg } \\
\text { etal. } \\
{[2001]}\end{array}$ & $\begin{array}{l}3660 \\
\text { crianças e } \\
\text { jovens dos } 5 \\
\text { aos } 19 \text { anos } \\
\text { dos dois } \\
\text { sexos. }\end{array}$ & $\begin{array}{l}\text { Estudo da } \\
\text { relação entre a } \\
\text { força muscular } \\
\text { estática e o ESE } \\
\text { de crianças e } \\
\text { jovens negros. }\end{array}$ & $\begin{array}{l}\text { Força de preensão } \\
\text { manual, prega } \\
\text { adiposa tricipital e } \\
\text { velocidade de } \\
\text { reacção. }\end{array}$ & $\begin{array}{l}\text { Os resultados revelaram uma } \\
\text { nítida vantagem na produção de } \\
\text { força muscular dos sujeitos de } \\
\text { ESE mais elevado. Os valores } \\
\text { médios superiores são mais } \\
\text { evidentes a partir da puberdade, } \\
\text { mesmo quando os dados se } \\
\text { ajustam à área de secção } \\
\text { transversal do músculo. }\end{array}$ & África do Sul \\
\hline $\begin{array}{l}\text { Saranga et } \\
\text { al. (2002) }\end{array}$ & $\begin{array}{l}2749 \\
\text { crianças e } \\
\text { jovens dos } 8 \\
\text { aos } 15 \text { anos } \\
\text { de ambos os } \\
\text { sexos. }\end{array}$ & $\begin{array}{l}\text { Estudo das } \\
\text { mudanças nos } \\
\text { níveis de } \\
\text { aptidão física } \\
\text { em função de } \\
\text { alterações } \\
\text { políticas e sócio- } \\
\text { económicas } \\
\text { havidas entre } \\
\text { 1992-99. }\end{array}$ & $\begin{array}{l}\text { A aptidão física foi } \\
\text { avaliada através } \\
\text { das provas de } \\
\text { flexibilidade, força } \\
\text { de resistência } \\
\text { muscular, força de } \\
\text { preensão manual, } \\
\text { corrida } 10 \times 5 \\
\text { metros e } \\
\text { resistência } \\
\text { cardiorespiratória. }\end{array}$ & $\begin{array}{l}\text { Constatou-se, em todas as } \\
\text { variáveis consideradas, uma } \\
\text { prestação dos sujeitos de } 1999 \\
\text { nitidamente inferior a dos de } \\
1992 \text { ( } \mathrm{p}=0.05 \text { ), há excepção do } \\
\text { teste de força de preensão } \\
\text { manual (hand grip). A drástica } \\
\text { mudança nos niveis sócio- } \\
\text { económicos dos sujeitos é } \\
\text { apontada, entre outros factores, } \\
\text { como sendo as causas primárias } \\
\text { deste quadro de resultados. }\end{array}$ & $\begin{array}{l}\text { Moçambique } \\
\text { (Maputo) }\end{array}$ \\
\hline
\end{tabular}


Quadro A4. Sinopse dos estudos sobre infecções parasitárias e aptidão física realizados em África.

\begin{tabular}{|c|c|c|c|c|c|}
\hline Autor(es) & Amostra & Objectivos & Variáveis & Resultados & País \\
\hline $\begin{array}{l}\text { Walker et al. } \\
\text { [1972] }\end{array}$ & $\begin{array}{l}329 \text { crianças dos } \\
14 \text { aos } 15 \text { anos } \\
\text { de ambos os } \\
\text { sexos. }\end{array}$ & $\begin{array}{l}\text { Avaliaram do } \\
\text { efeito da } \\
\text { bilharziose na } \\
\text { capacidade física. }\end{array}$ & $\begin{array}{l}\text { Peso, altura, } \\
\text { pregas adiposas } \\
\text { tricipital e } \\
\text { subescapular e o } \\
\text { teste de } 12 \\
\text { minutos de } \\
\text { corrida/marcha. }\end{array}$ & $\begin{array}{l}\text { Os resultados } \\
\text { evidenciaram uma } \\
\text { semelhança estatística } \\
\text { entre as médias do grupo } \\
\text { de crianças infectadas e o } \\
\text { das não infectadas, tanto } \\
\text { a nivel das medidas } \\
\text { somáticas como a nivel da } \\
\text { performance de corrida. }\end{array}$ & África do Sul \\
\hline $\begin{array}{l}\text { Davies } \\
\text { [1973] }\end{array}$ & Crianças & $\begin{array}{l}\text { Estudo do efeito } \\
\text { da bilharziose na } \\
\text { resposta } \\
\text { cardiorespiratória } \\
\text { ao exercício. }\end{array}$ & $\begin{array}{l}\text { Peso, altura, } \\
\text { pregas adiposas e } \\
\text { aptidão } \\
\text { cardiorespiratória. }\end{array}$ & $\begin{array}{l}\text { Não foram encontradas } \\
\text { diferenças entre o grupo } \\
\text { de crianças infectadas e o } \\
\text { das não infectadas. }\end{array}$ & Tanzânia \\
\hline $\begin{array}{l}\text { Stephenson } \\
\text { et al. [1985] }\end{array}$ & Crianças & $\begin{array}{l}\text { Estudo do efeito } \\
\text { da bilharziose na } \\
\text { aptidão física. }\end{array}$ & $\begin{array}{l}\text { Indicadores } \\
\text { somáticos, } \\
\text { parasitologia e } \\
\text { aptidão física. }\end{array}$ & $\begin{array}{l}\text { Foram encontradas } \\
\text { evidências de que altos } \\
\text { indices de infecção } \\
\text { tinham um efeito negativo } \\
\text { na aptidão fisica, para } \\
\text { além de causarem perda } \\
\text { urinária de ferro. }\end{array}$ & Duénia \\
\hline $\begin{array}{l}\text { Ndamba } \\
\text { (1986) }\end{array}$ & Crianças & $\begin{array}{l}\text { Estudo do efeito } \\
\text { da bilharziose na } \\
\text { aptidão } \\
\text { cardiorespiratória. }\end{array}$ & $\begin{array}{l}\text { Indicadores } \\
\text { somáticos, } \\
\text { parasitologia e } \\
\text { prova de corrida. }\end{array}$ & $\begin{array}{l}\text { Crianças não infectadas e } \\
\text { criaç̧as fortemente } \\
\text { infectadas depois de } \\
\text { tratamento evidenciavam } \\
\text { uma melhor resistência } \\
\text { cardiorespiratória, em } \\
\text { relação às crianças } \\
\text { infectadas antes de } \\
\text { tratamento }\end{array}$ & Zimbabwé \\
\hline $\begin{array}{l}\text { Collins et al. } \\
\text { (1988) }\end{array}$ & $\begin{array}{l}\text { Cortadores de } \\
\text { cana }\end{array}$ & $\begin{array}{l}\text { Estudo do efeito } \\
\text { da bilharziose na } \\
\text { capacidade } \\
\text { produtiva. } \\
\end{array}$ & $\begin{array}{l}\text { Peso, altura, } \\
\text { pregas adiposas e } \\
\text { produtividade. }\end{array}$ & $\begin{array}{l}\text { Não foi encontrado } \\
\text { qualquer efeito negativo } \\
\text { da bilharziose na } \\
\text { produtividade. }\end{array}$ & Sudão \\
\hline $\begin{array}{l}\text { Stephenson } \\
\text { [1989] }\end{array}$ & Crianças & $\begin{array}{l}\text { Avaliação da } \\
\text { bilharziose e sua } \\
\text { relação com } \\
\text { aspectos } \\
\text { nutricionais. }\end{array}$ & $\begin{array}{l}\text { Indicadores } \\
\text { somáticos, } \\
\text { parasitologia, } \\
\text { apetite e aptidão } \\
\text { física. }\end{array}$ & $\begin{array}{l}\text { Após o tratamento, as } \\
\text { crianças infectadas para } \\
\text { além de melhorarem os } \\
\text { seus níveis de aptidão } \\
\text { fisica, evidenciaram ainda } \\
\text { um maior apetite, } \\
\text { melhores taxas de } \\
\text { crescimento e revelaram. } \\
\text { se mais activas. }\end{array}$ & Quénia \\
\hline $\begin{array}{l}\text { Latham et al. } \\
{[1990]}\end{array}$ & Crianças & $\begin{array}{l}\text { Estudo do efeito } \\
\text { da bilharziose na } \\
\text { aptidão aeróbia. }\end{array}$ & $\begin{array}{l}\text { Indicadores } \\
\text { somáticos, } \\
\text { parasitologia e } \\
\text { teste de degrau } \\
\text { de Harvard. }\end{array}$ & $\begin{array}{l}\text { Crianças infectadas } \\
\text { exibiram após o } \\
\text { tratamento resultados } \\
\text { mais altos no teste de } \\
\text { degrau de Harvard. }\end{array}$ & Ouénia \\
\hline
\end{tabular}




\begin{tabular}{|c|c|c|c|c|c|}
\hline $\begin{array}{l}\text { Stephenson } \\
\text { et al. (1990) }\end{array}$ & $\begin{array}{l}33 \text { rapazes dos } 6 \\
\text { aos } 12 \text { anos } \\
\text { infectados com } \\
\text { hookworm, } \\
\text { Trichuris } \\
\text { trichiurae } \\
\text { Ascaris } \\
\text { lumbricoides }\end{array}$ & $\begin{array}{l}\text { Determinação do } \\
\text { efeito de? } \\
\text { semanas no } \\
\text { tratamento da } \\
\text { bilharziose na } \\
\text { aptidão física. }\end{array}$ & $\begin{array}{l}\text { Indicadores } \\
\text { somáticos, } \\
\text { parasitologia e } \\
\text { teste de degrau } \\
\text { de Harvard. }\end{array}$ & $\begin{array}{l}\text { 0 grupo de albendazole } \\
\text { reduziu em } 80 \% \text { e } 100 \% \text { a } \\
\text { prevalência e a } \\
\text { intensidade de infecção } \\
\text { de Hookworm e de } A \text {. } \\
\text { Lumbricoides contra } 17 \% \\
\text { e } 20 \% \text { de aumento } \\
\text { verificados no grupo de } \\
\text { placebo, respectivamente } \\
\text { e } 78 \% \text { das crianças } \\
\text { tratadas melhoraram a } \\
\text { aptidão cardiorespiratória } \\
\text { contra } 33 \% \text { dos rapazes do } \\
\text { grupo de placebo. }\end{array}$ & Ouénia \\
\hline $\begin{array}{l}\text { Stephenson } \\
\text { et al. (1993) }\end{array}$ & $\begin{array}{l}53 \text { rapazes } \\
\text { Quenianos } \\
\text { infectados com } \\
\text { Hookworm, } \\
\text { Trichurise } \\
\text { Ascaris }\end{array}$ & $\begin{array}{l}\text { Determinação do } \\
\text { efeito de } 4 \text { meses } \\
\text { no tratamento da } \\
\text { bilharziase com } \\
\text { uma simples dose } \\
\text { de } 600 \text {-mg de } \\
\text { albendazole na } \\
\text { aptidão física. }\end{array}$ & $\begin{array}{l}\text { Indicadores } \\
\text { somáticos, } \\
\text { parasitologia e } \\
\text { teste de degrau } \\
\text { de Harvard. }\end{array}$ & $\begin{array}{l}\text { O grupo experimental } \\
\text { apresentou uma redução } \\
\text { significativa de } \\
\text { prevalência e de } \\
\text { intensidade de infecção } \\
\text { de Hookworm, } A \text {. } \\
\text { Lumbricoides e Trichuris } \\
\text { [ } 81 \%, 99 \% \text { e } 39 \% \text { vs } 31 \% \text {, } \\
27 \% \text { e } 1 \% \text { ) e melhorou } \\
\text { significativamente os } \\
\text { seus valores somáticos e } \\
\text { de aptidão física. }\end{array}$ & Ouénia \\
\hline $\begin{array}{l}\text { Ndamba et al. } \\
\text { [1993] }\end{array}$ & $\begin{array}{l}497 \text { adultos } \\
\text { cortadores de } \\
\text { cana-de-açúcar, } \\
\text { dos quais } 28 ? \\
\text { infectados com } \\
\text { Schistosoma } \\
\text { Mansoni. }\end{array}$ & $\begin{array}{l}\text { Avaliação do } \\
\text { estado infeccioso } \\
\text { na capacidade } \\
\text { fisica e } \\
\text { produtividade. }\end{array}$ & $\begin{array}{l}\text { Indicadores } \\
\text { somáticos, } \\
\text { parasitologia, } \\
\text { produtividade e } \\
\text { aptidão física. }\end{array}$ & $\begin{array}{l}\text { A aptidão física dos } \\
\text { trabalhadores infectados } \\
\text { melhorou em } 4.3 \% \text { e a } \\
\text { produtividade em } 16.6 \% \\
\text { após } 16 \text { semanas de } \\
\text { tratamento. }\end{array}$ & Zimbabwé \\
\hline
\end{tabular}




\section{Quadro-A5: Sinopse dos estudos sobre actividade física realizados em África}

\begin{tabular}{|c|c|c|c|c|c|}
\hline Autor[es] & Amostra & Objectivos & Variáveis & Resultados & País \\
\hline $\begin{array}{l}\text { Noakes et } \\
\text { al. (1986) }\end{array}$ & $\begin{array}{l}7188 \text { sul- } \\
\text { africanos } \\
\text { caucasianos } \\
\text { de ambos os } \\
\text { sexos dos } 15 \\
\text { aos } 64 \text { anos } \\
\text { provenientes } \\
\text { de três zonas } \\
\text { rurais. }\end{array}$ & $\begin{array}{l}\text { Determinar a } \\
\text { relação entre os } \\
\text { baixos niveis de } \\
\text { dispêndio } \\
\text { energético no } \\
\text { trabalho e no } \\
\text { lazer e elevadas } \\
\text { taxas de } \\
\text { prevalência de } \\
\text { doença } \\
\text { cardiovascular. }\end{array}$ & $\begin{array}{l}\text { Actividade física } \\
\text { avaliada através } \\
\text { de questionário- } \\
\text { entrevista e o } \\
\text { dispêndio } \\
\text { energético. }\end{array}$ & $\begin{array}{l}\text { Em todas as idades, e em ambos } \\
\text { os sexos, menos de } 1 \% \text { dos } \\
\text { sujeitos avaliados executaram } \\
\text { tarefas que requeriam taxas } \\
\text { elevadas de dispêndio energético. } \\
\text { A partir da idade dos } 24 \text { registou- } \\
\text { se um decréscimo acentuado da } \\
\text { participação em actividades } \\
\text { moderadas e vigorosas durante o } \\
\text { tempo de lazer e acima dos } 44 \\
\text { anos menos de } 26 \% \text { dos homens e } \\
\text { menos de } 16 \% \text { das mulheres } \\
\text { excedem a quantidade de } 8400 \mathrm{KJ} \\
\text { semanais de dispêndio energético } \\
\text { durante o tempo de lazer. }\end{array}$ & África do Sul \\
\hline $\begin{array}{l}\text { Bénéfice } \\
\text { (1992) }\end{array}$ & $\begin{array}{l}100 \text { crianças } \\
\text { de ambos os } \\
\text { sexos dos } 10 \\
\text { aos } 13 \text { anos. }\end{array}$ & $\begin{array}{l}\text { Estudo dos } \\
\text { efeitos da má } \\
\text { nutrição crónica } \\
\text { na funcionalidade } \\
\text { e nos padrões de } \\
\text { actividade física. }\end{array}$ & $\begin{array}{l}\text { Medidas } \\
\text { antropométricas, } \\
\text { actividade física } \\
\text { avaliada através } \\
\text { da monitorização } \\
\text { da frequência } \\
\text { cardiaca minuto a } \\
\text { minuto durante } 6 \\
\text { horas, } \\
\text { funcionalidade } \\
\text { avaliada através } \\
\text { de um teste } \\
\text { submaximal de } \\
\text { degrau e quatro } \\
\text { testes motores. }\end{array}$ & $\begin{array}{l}\text { Valores de peso de dois terços da } \\
\text { amostra abaixo de - } 1 \text { DP das } \\
\text { normas de WHO/NCHS referentes } \\
\text { àquelas idades. As crianças } \\
\text { estudadas evidenciaram } \\
\text { resultados inferiores em todos os } \\
\text { testes realizados, assim como } \\
\text { níveis inferiores de actividade } \\
\text { física comparativamente às } \\
\text { crianças dos países } \\
\text { desenvolvidos. }\end{array}$ & Senegal \\
\hline $\begin{array}{l}\text { Sparling et } \\
\text { al. (1994) }\end{array}$ & $\begin{array}{l}212 \text { sujeitos } \\
\text { negros sul- } \\
\text { africanos do } \\
\text { sexo } \\
\text { masculino } \\
\text { dos } 25 \text { aos } \\
64 \text { anos. }\end{array}$ & $\begin{array}{l}\text { Estudo da } \\
\text { associação entre } \\
\text { a actividade fisica } \\
\text { e os factores de } \\
\text { risco de doença } \\
\text { cardiovascular. }\end{array}$ & $\begin{array}{l}\text { Altura, peso, } \\
\text { perimetro } \\
\text { braquial, pressão } \\
\text { arterial, colesterol } \\
\text { total, HDL- } \\
\text { colesterol e } \\
\text { actividade física } \\
\text { medida por } \\
\text { questionário- } \\
\text { entrevista. }\end{array}$ & $\begin{array}{l}43 \% \text { dos sujeitos da amostra } \\
\text { tinham empregos que requeriam } \\
\text { uma actividade fisica moderada a } \\
\text { vigorosa e que os perfis de } \\
\text { concentração de lípidos se } \\
\text { associavam a niveis baixo a } \\
\text { moderados de exercicio habitual. }\end{array}$ & África do Sul \\
\hline $\begin{array}{l}\text { Prista et al. } \\
\text { [1997] }\end{array}$ & $\begin{array}{l}593 \text { crianças } \\
\text { e jovens dos } \\
8 \text { aos } 15 \\
\text { anos de } \\
\text { ambos os } \\
\text { sexos. }\end{array}$ & $\begin{array}{l}\text { Avaliação da } \\
\text { actividade física } \\
\text { habitual através } \\
\text { de um } \\
\text { questionário } \\
\text { concebido para } \\
\text { esta população } \\
\text { (validado em } \\
\text { 2000,Prista et } \\
\text { al., 2000). }\end{array}$ & $\begin{array}{l}\text { Peso, Altura, pregas } \\
\text { adiposas, } \\
\text { composição } \\
\text { corporal, estatuto } \\
\text { sócio-económico, } \\
5 \text { testes motores } \\
\text { e actividade física } \\
\text { habitual. }\end{array}$ & $\begin{array}{l}\text { Os resultados revelaram que (1) } \\
\text { as crianças e jovens de Maputo } \\
\text { demonstravam hábitos de } \\
\text { actividade intensas } \\
\text { caracterizados por tarefas de } \\
\text { sobrevivência não mecanizadas e } \\
\text { jogos ao ar livre; (2) as raparigas e } \\
\text { os mais desfavorecidos } \\
\text { apresentavam niveis de actividade } \\
\text { mais intensos que os rapazes e os } \\
\text { sócio-economicamente mais } \\
\text { favorecidos. }\end{array}$ & $\begin{array}{l}\text { Moçambique } \\
\text { (Maputo) }\end{array}$ \\
\hline
\end{tabular}




\begin{tabular}{|c|c|c|c|c|c|}
\hline $\begin{array}{l}\text { Bénéfice \& } \\
\text { Cames } \\
\text { [1999] }\end{array}$ & $\begin{array}{l}40 \text { raparigas } \\
\text { adolescentes } \\
\text { senegalesas } \\
\text { rurais com } \\
13.5 \pm 0.5 \\
\text { anos de } \\
\text { idade. }\end{array}$ & $\begin{array}{l}\text { Comparação dos } \\
\text { padrões de } \\
\text { actividade física e } \\
\text { as estimativas } \\
\text { diárias de } \\
\text { dispêndio entre } \\
\text { época seca e } \\
\text { chuvosa. }\end{array}$ & $\begin{array}{l}\text { Dispêndio } \\
\text { energético e } \\
\text { actividade física } \\
\text { avaliada através } \\
\text { de acelerómetros } \\
\text { durante quatro } \\
\text { dias consecutivos } \\
\text { e sempre à } \\
\text { mesma hora, e } \\
\text { através de uma } \\
\text { observação } \\
\text { directa durante } \\
\text { dois dias } \\
\text { consecutivos. }\end{array}$ & $\begin{array}{l}\text { Os niveis de actividade fisica } \\
\text { durante o dia derivados da } \\
\text { quantidade de movimentos } \\
\text { registados foram mais altos } \\
\text { durante a época chuvosa que } \\
\text { durante a época seca. }\end{array}$ & Senegal \\
\hline $\begin{array}{l}\text { Garnier \& } \\
\text { Bénéfice } \\
\text { [2001] }\end{array}$ & $\begin{array}{l}80 \text { raparigas } \\
\text { rurais com } \\
14.4 \pm 0.5 \\
\text { anos de } \\
\text { idade. }\end{array}$ & $\begin{array}{l}\text { Estudo da } \\
\text { actividade física } \\
\text { em função da } \\
\text { zona geográfica e } \\
\text { do seu impacto } \\
\text { no crescimento e } \\
\text { no estado } \\
\text { nutricional. }\end{array}$ & $\begin{array}{l}\text { Peso, altura, } \\
\text { pregas de } \\
\text { adiposidade, } \\
\text { maturação sexual, } \\
\text { estado nutricional } \\
\text { e actividade física. }\end{array}$ & $\begin{array}{l}\text { As adolescentes estudadas eram } \\
\text { mais baixas, magras e com um } \\
\text { atraso maturacional em relação às } \\
\text { raparigas dos paises } \\
\text { desenvolvidos do mesmo intervalo } \\
\text { etário. As raparigas migrantes } \\
\text { pesaram } 3.5 \mathrm{Kg} \text { a mais em relação } \\
\text { as raparigas rurais e apresentaram } \\
\text { maiores valores de gordura } \\
\text { corporal. }\end{array}$ & Senegal \\
\hline $\begin{array}{l}\text { Bénéfice et } \\
\text { al. [2001) }\end{array}$ & $\begin{array}{l}40 \text { raparigas } \\
\text { rurais com } \\
13.3 \pm 0.5 \\
\text { anos de } \\
\text { idade }\end{array}$ & $\begin{array}{l}\text { Estudo } \\
\text { longitudinal da } \\
\text { actividade física e } \\
\text { sua relação com a } \\
\text { maturação, } \\
\text { crescimento e } \\
\text { estado } \\
\text { nutricional. }\end{array}$ & $\begin{array}{l}\text { Peso, altura, } \\
\text { pregas de } \\
\text { adiposidade } \\
\text { subcutâneas, } \\
\text { estatuto } \\
\text { maturacional, } \\
\text { estado nutricional } \\
\text { e a actividade } \\
\text { física avaliada } \\
\text { através de } \\
\text { acelerómetros. }\end{array}$ & $\begin{array}{l}\text { Os resultados encontrados } \\
\text { revelaram elevados niveis de } \\
\text { dispêndio energético e niveis de } \\
\text { actividade fisica diária que } \\
\text { variaram entre } 1.70 \text { e } 1.85 \\
\text { múltiplos da taxa de metabolismo } \\
\text { basal. Os niveis de actividade } \\
\text { fisica registaram uma redução em } \\
\text { função da idade. }\end{array}$ & Senegal \\
\hline $\begin{array}{l}\text { Bénéfice et } \\
\text { al. [2001b] }\end{array}$ & $\begin{array}{l}40 \text { raparigas } \\
\text { rurais com } \\
13.3 \pm 0.5 \\
\text { anos de } \\
\text { idade }\end{array}$ & $\begin{array}{l}\text { Estudo da relação } \\
\text { entre a idade, } 0 \\
\text { estatuto } \\
\text { maturacional, a } \\
\text { composição } \\
\text { corporal e os } \\
\text { niveis de } \\
\text { actividade física. }\end{array}$ & $\begin{array}{l}\text { Peso, altura, } \\
\text { pregas de } \\
\text { adiposidade } \\
\text { subcutâneas, } \\
\text { estado } \\
\text { maturacional, } \\
\text { estado nutricional } \\
\text { e actividade física, } \\
\text { avaliada durante } \\
\text { três anos } \\
\text { consecutivos, } \\
\text { através do registo } \\
\text { dos movimentos } \\
\text { minuto-a-minuto } \\
\text { por meio de } \\
\text { acelerómetros. }\end{array}$ & $\begin{array}{l}\text { Foi encontrada uma correlação } \\
\text { significativa e positiva entre o IMC } \\
\text { e a actividade física durante o dia, } \\
\text { enquanto que durante a noite foi } \\
\text { encontrada uma correlação } \\
\text { positiva entre a actividade física e } \\
\text { a gordura corporal e a massa } \\
\text { isenta de gordura. }\end{array}$ & Senegal \\
\hline
\end{tabular}




\begin{tabular}{|c|c|c|c|c|c|c|}
\hline o-A5 (cont.) & $\begin{array}{l}\text { Garnier et } \\
\text { al. (2003) }\end{array}$ & $\begin{array}{l}80 \text { raparigas } \\
\text { rurais com } \\
14.4 \pm 0.5 \\
\text { anos de } \\
\text { idade. }\end{array}$ & $\begin{array}{l}\text { Estudo da } \\
\text { influência da } \\
\text { migração urbana } \\
\text { na actividade } \\
\text { física, no estado } \\
\text { nutricional e no } \\
\text { crescimento. }\end{array}$ & $\begin{array}{l}\text { Peso, altura, } \\
\text { pregas de } \\
\text { adiposidade } \\
\text { subcutâneas, } \\
\text { perímetro braquial } \\
\text { e actividade física } \\
\text { avaliada através } \\
\text { de acelerómetros } \\
\text { e questionário. }\end{array}$ & $\begin{array}{l}\text { As raparigas migrantes revelaram. } \\
\text { se mais activas que as nảo- } \\
\text { migrantes ( } p<0.0001 \text { ). A migração } \\
\text { urbana resultou numa puberdade } \\
\text { avançada e na melhoria do estado } \\
\text { nutricional. }\end{array}$ & Senegal \\
\hline & $\begin{array}{l}\text { Micklesfield } \\
\text { etal. } \\
\text { [2003] }\end{array}$ & $\begin{array}{l}144 \\
\text { mulheres } \\
\text { sul-africanas } \\
\text { com } \\
42.6 \pm 8.9 \\
\text { anos de } \\
\text { idade. }\end{array}$ & $\begin{array}{l}\text { Estudo da relação } \\
\text { entre a densidade } \\
\text { mineral óssea e a } \\
\text { actividade física } \\
\text { ao longo da vida. }\end{array}$ & $\begin{array}{l}\text { Densidade } \\
\text { mineral óssea } \\
\text { avaliada através } \\
\text { de DEXA, } \\
\text { actividade física } \\
\text { avaliada através } \\
\text { de um } \\
\text { questionário e } \\
\text { dispêndio } \\
\text { energético total } \\
\text { em MET/hrs. }\end{array}$ & $\begin{array}{l}\text { Foi encontrada uma associação } \\
\text { entre as actividades com impacto } \\
\text { na idade jovem e uma elevada } \\
\text { densidade mineral óssea em } \\
\text { idades mais avançadas. }\end{array}$ & África do Sul \\
\hline & $\begin{array}{l}\text { McVeigh et } \\
\text { al. }(2004)\end{array}$ & $\begin{array}{l}\text { Crianças de } \\
\text { raça negra e } \\
\text { caucasiana } \\
\text { de } 9 \text { anos de } \\
\text { idade. }\end{array}$ & $\begin{array}{l}\text { Estudo } \\
\text { comparativo da } \\
\text { relação entre a } \\
\text { densidade } \\
\text { mineral óssea e a } \\
\text { actividade física } \\
\text { entre crianças } \\
\text { negras e } \\
\text { caucasianas. }\end{array}$ & $\begin{array}{l}\text { Densidade } \\
\text { mineral óssea } \\
\text { avaliada através } \\
\text { de DEXA e } \\
\text { actividade física } \\
\text { foi estimada de } \\
\text { acordo com as } \\
\text { componentes } \\
\text { metabólica e } \\
\text { mecânica. }\end{array}$ & $\begin{array}{l}\text { Foram encontradas diferenças } \\
\text { étnicas nos padrões de actividade } \\
\text { física, tendo as crianças } \\
\text { caucasianas dispendido valores } \\
\text { mais elevados de energia em } \\
\text { relação as crianças negras } \\
{[21.7 \pm 2.9 \text { vs } 9.5 \pm 0.5 ; p<0.001] \text {. }}\end{array}$ & África do Sul \\
\hline
\end{tabular}

